\title{
Guidelines
}

\section{The 2014 Canadian Hypertension Education Program Recommendations for Blood Pressure Measurement, Diagnosis, Assessment of Risk, Prevention, and Treatment of Hypertension}

Kaberi Dasgupta, MD, MSc, ${ }^{a}$ Robert R. Quinn, MD, PhD, ${ }^{b}$ Kelly B. Zarnke, MD, MSc, ${ }^{c}$

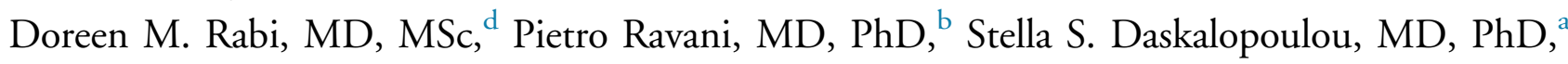
Simon W. Rabkin, MD, ${ }^{\mathrm{e}}$ Luc Trudeau, MD, ${ }^{\mathrm{f}}$ Ross D. Feldman, MD, ${ }^{\mathrm{g}}$ Lyne Cloutier, RN, PhD,

Ally Prebtani, MD, ${ }^{i}$ Robert J. Herman, MD, ${ }^{j}$ Simon L. Bacon, PhD, ${ }^{k}$

Richard E. Gilbert, MD, PhD, ${ }^{1}$ Marcel Ruzicka, MD, PhD, ${ }^{\mathrm{m}}$ Donald W. McKay, PhD, ${ }^{\mathrm{n}}$

Tavis S. Campbell, PhD, ${ }^{\circ}$ Steven Grover, MD, MPA, ${ }^{\mathrm{p}}$ George Honos, MD, ${ }^{\mathrm{q}}$

Ernesto L. Schiffrin, MD, PhD, ${ }^{r}$ Peter Bolli, MD, ${ }^{s}$ Thomas W. Wilson, MD,

Patrice Lindsay, RN, PhD, ${ }^{\mathrm{u}}$ Michael D. Hill, MD, MSc, ${ }^{\mathrm{v}}$ Shelagh B. Coutts, MD, ${ }^{\mathrm{w}}$

Gord Gubitz, MD, ${ }^{\mathrm{x}}$ Mark Gelfer, MD, ${ }^{\mathrm{y}}$ Michel Vallée, MD, PhD,

G.V. Ramesh Prasad, MBBS, MSc, ${ }^{\text {aa }}$ Marcel Lebel, MD, ${ }^{\text {bb }}$ Donna McLean, RN, NP, PhD, ${ }^{c c}$ J. Malcolm O. Arnold, MD, ${ }^{\mathrm{dd}}$ Gordon W. Moe, MD, MSc, ${ }^{\text {ee }}$ Jonathan G. Howlett, MD, ${ }^{\mathrm{ff}}$ Jean-Martin Boulanger, MD, ${ }^{g g}$ Pierre Larochelle, MD, ${ }^{\text {hh }}$ Lawrence A. Leiter, MD, ${ }^{\text {ii }}$

Charlotte Jones, MD, PhD, ${ }^{\mathrm{jj}}$ Richard I. Ogilvie, MD, ${ }^{\mathrm{kk}}$ Vincent Woo, MD,

Janusz Kaczorowski, PhD, ${ }^{\mathrm{mm}}$ Kevin D. Burns, MD, ${ }^{\mathrm{nn}}$ Robert J. Petrella, MD, PhD, ${ }^{\text {oo }}$ Swapnil Hiremath, MD, MPH, ${ }^{\mathrm{pp}}$ Alain Milot, MD, MSc, ${ }^{\mathrm{qq}}$ James A. Stone, MD, PhD, ${ }^{\mathrm{rr}}$

Denis Drouin, $\mathrm{MD},{ }^{\mathrm{ss}} \mathrm{Kim}$ L. Lavoie, $\mathrm{PhD},{ }^{\mathrm{tt}}$ Maxime Lamarre-Cliche, MD, ${ }^{\mathrm{uu}}$ Guy Tremblay, MD, ${ }^{\mathrm{vv}}$ Pavel Hamet, MD, PhD, ${ }^{\mathrm{ww}}$ George Fodor, MD, PhD,

S. George Carruthers, MD, ${ }^{y y}$ George B. Pylypchuk, MD, ${ }^{\text {zz }}$ Ellen Burgess, MD, ${ }^{\text {aaa }}$

Richard Lewanczuk, MD, PhD, ${ }^{\text {bb }}$ George K. Dresser, MD, PhD, ${ }^{\text {ccc }}$ S. Brian Penner, MD, ${ }^{\text {ddd }}$

Robert A. Hegele, MD, ${ }^{\text {ee }}$ Philip A. McFarlane, MD, PhD, ${ }^{\text {fff }}$ Milan Khara, MBChB, ${ }^{g g g}$ Andrew Pipe, CM, MD, ${ }^{\text {hhh }}$ Paul Oh, MD, MSc, ${ }^{\text {iii }}$ Peter Selby, MBBS, MHSc, jij Mukul Sharma, MD, MSc, ${ }^{\text {kk }}$ Debra J. Reid, PhD, RD, ${ }^{111}$

\footnotetext{
Received for publication January 23, 2014. Accepted February 3, 2014.

Corresponding author: Dr Kaberi Dasgupta, Division of Clinical Epidemiology, Department of Medicine, McGill University Health Centre, 687 Pine Ave West, V-Building (V1.08), Montreal, Québec H3A 1A1, Canada. Tel.: +1-514-934-1934 ×44715; fax: +1-514-934-8293.

E-mail: kaberi.dasgupta@mcgill.ca

See page 500 for disclosure information.

A version of the hypertension recommendations designed for patient and public education has been developed to assist health care practitioners managing hypertension. The summary is available electronically (go to http://www.hypertension.ca or http://www.heartandstroke.ca).
} 


\title{
Sheldon W. Tobe, MD, MSc(HPTE), ${ }^{\mathrm{mmm}}$ Raj S. Padwal, MD, MSc, ${ }^{\text {nnn }}$ and Luc Poirier, BPharm, MSc; ${ }^{\circ o o}$ for the Canadian Hypertension Education Program
}

\begin{abstract}
${ }^{a}$ Divisions of General Internal Medicine, Clinical Epidemiology and Endocrinology, Department of Medicine, McGill University, McGill University Health Centre, Montreal, Québec, Canada; ${ }^{b}$ Division of Nephrology, Department of Medicine, and Department of Community Health Sciences, Foothills Medical Centre, University of Calgary, Calgary, Alberta, Canada; ${ }^{c}$ Division of General Internal Medicine, University of Calgary, Calgary, Alberta, Canada; ${ }^{d}$ Departments of Medicine, Community Health, and Cardiac Sciences, University of Calgary, Calgary, Alberta, Canada; ${ }^{\circ}$ Vancouver Hospital, University of British Columbia, Vancouver, British Columbia, Canada, ${ }^{f}$ Division of Internal Medicine, McGill University, Montréal, Québec, Canada $;{ }^{g}$ Western University, London, Ontario, Canada $;{ }^{h}$ Université du Québec à TroisRivières, Trois-Rivières, Québec, Canada; ${ }^{i}$ McMaster University, Hamilton, Ontario, Canada, ${ }^{j}$ University of Calgary, Calgary, Alberta, Canada ${ }^{k}$ Montreal Behavioural Medicine Centre, Concordia University and Hôpital du Sacré-Coeur de Montréal, Montréal, Québec, Canada; ' University of Toronto, Division of Endocrinology, St Michael's Hospital, Toronto, Ontario, Canada; ${ }^{m}$ Division of Nephrology, Department of Medicine, Ottawa Hospital Research Institute, University of Ottawa, Ottawa, Ontario, Canada; ${ }^{n}$ Faculty of Medicine, Memorial University of Newfoundland, St John's, Newfoundland and Labrador, Canada; ${ }^{\circ}$ Department of Psychology, University of Calgary, Calgary, Alberta, Canada; ${ }^{p}$ Division of Clinical Epidemiology, Montreal General Hospital, Montreal, Québec, Canada; ${ }^{q}$ University of Montreal, Montreal, Québec, Canada; ${ }^{r}$ Department of Medicine and Lady Davis Institute for Medical Research, Jewish General Hospital, McGill University, Montreal, Québec, Canada: ${ }^{s}$ Ambulatory Internal Medicine Teaching Clinic, St Catharines, Ontario, Canada; ${ }^{t}$ Department of Medicine, University of Saskatchewan, Saskatoon, Saskatchewan,

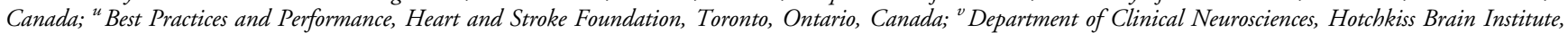
University of Calgary, Calgary, Alberta, Canada; ${ }^{w}$ Departments of Clinical Neurosciences and Radiology, Hotchkiss Brain Institute, University of Calgary, Calgary, Alberta, Canada; ${ }^{x}$ Division of Neurology, Halifax Infirmary, Dalhousie University, Halifax, Nova Scotia, Canada; ${ }^{y}$ Department of Family Medicine, University of British Columbia, Copeman Healthcare Centre, Vancouver, British Columbia, Canada; ${ }^{z}$ Hôpital Maisonneuve-Rosemont, Université de Montréal, Montréal, Québec, Canada; ${ }^{a}$ University of Toronto, Toronto, Ontario, Canada; ${ }^{b b}$ Department of Medicine, l'Université Laval, Québec, Québec, Canada; ${ }^{c}$ University of Alberta, Edmonton, Alberta, Canada; ${ }^{d d}$ Western University, London, Ontario, Canada; ${ }^{e e}$ St Michael's Hospital, University of Toronto, Toronto, Ontario, Canada; ${ }^{f f}$ Department of Medicine, University of Calgary, Calgary, Ontario, Canada; ${ }^{g s}$ Charles LeMoyne Hospital Research Centre, Sherbrooke University, Sherbrooke, Québec, Canada; ${ }^{2 h}$ Institut de recherches cliniques de Montréal, Université de Montréal, Montréal, Québec, Canada; ${ }^{i i}$ Keenan Research Centre in the Li Ka Shing Knowledge Institute of St Michael's Hospital, and University of Toronto, Toronto, Ontario, Canada; ${ }^{j j}$ Southern Medical Program, University of British Columbia, Okanagan Campus, Kelowna, British Columbia, Canada, ${ }^{k k}$ University Health Network, Departments of Medicine and Pharmacology, University of Toronto, Toronto, Ontario, Canada; "University of Manitoba, Winnipeg, Manitoba, Canada; ${ }^{m m}$ Université de Montréal and CHUM, Montréal, Québec, Canada; ${ }^{n n}$ Ottawa Hospital Research Institute, Ottawa, Ontario, Canada; ${ }^{o o}$ Department of Family Medicine, Western University, London, Ontario, Canada; ${ }^{p p}$ Division of Nephrology, University of Ottawa, Ottawa, Ontario, Canada; ${ }^{q q}$ Department of Medicine, Université Laval, Québec, Québec, Canada; ${ }^{r r}$ Division of Cardiology, Department of Medicine, University of Calgary, Calgary, Alberta,

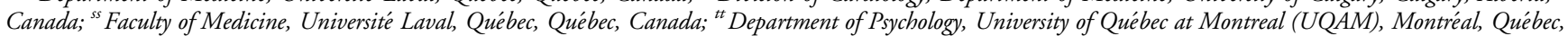
Canada; ${ }^{u u}$ Institut de Recherches Cliniques de Montréal, Université de Montréal, Québec, Canada; ${ }^{v v}$ CHU-Québec-Hopital St Sacrement, Québec, Québec, Canada; ${ }^{w w}$ Faculté de Médicine, Université de Montréal and Centre hospitalier de l'Université de Montréal (CHUM), Montréal, Québec, Canada; ${ }^{x x}$ University of Ottawa Heart Institute, Ottawa, Ontario, Canada; ${ }^{y y}$ Lisburn, Northern Ireland, UK; ${ }^{z z}$ Department of Medicine, University of Saskatchewan, Saskatoon, Saskatchewan, Canada; ${ }^{a a a}$ Faculty of Medicine, University of Calgary, Calgary, Alberta, Canada; ${ }^{\text {bbb }}$ University of Alberta, Edmonton, Alberta, Canada; ${ }^{c c c}$ Schulich School of Medicine and Dentistry, Western University, London, Ontario, Canada; ddd Department of Internal Medicine, University of Manitoba, Winnipeg, Manitoba, Canada; ${ }^{e e e}$ Departments of Medicine (Division of Endocrinology) and Biochemistry, Western University, London, Ontario, Canada; Af Division of Nephrology, St Michael's Hospital, University of Toronto, Toronto, Ontario, Canada; ${ }^{g 8 g}$ Vancouver Coastal Health Addiction Services, Faculty of Medicine, University of British Columbia, Vancouver, British Columbia,

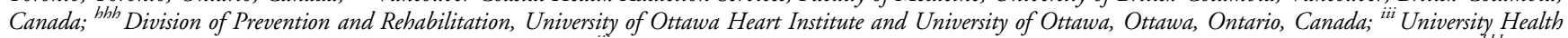
Network, University of Toronto, Toronto, Ontario, Canada; ijj Centre for Addiction and Mental Health, University of Toronto, Toronto, Ontario, Canada; ${ }^{k k k}$ The Canadian Stroke Network, Ottawa, Ontario, Canada; "ll Canadian Forces Health Services, Department of National Defence and Dietitians of Canada, Ottawa, Ontario, Canada; ${ }^{m m m}$ Northern Ontario School of Medicine, Greater Sudbury, Ontario, and University of Toronto, Toronto, Ontario, Canada; ${ }^{n n n}$ Department of Medicine, University of Alberta, Edmonton, Alberta, Canada; ${ }^{o o o}$ Centre Hospitalier Universitaire de Québec et Faculté de Pharmacie, Université Laval, Québec, Québec, Canada
\end{abstract}

\section{ABSTRACT}

Herein, updated evidence-based recommendations for the diagnosis, assessment, prevention, and treatment of hypertension in Canadian adults are detailed. For 2014, 3 existing recommendations were modified and 2 new recommendations were added. The following recommendations were modified: (1) the recommended sodium intake threshold was changed from $\leq 1500 \mathrm{mg}$ ( $3.75 \mathrm{~g}$ of salt) to approximately $2000 \mathrm{mg}$ (5 g of salt) per day; (2) a pharmacotherapy treatment initiation systolic blood pressure threshold of $\geq 160 \mathrm{~mm} \mathrm{Hg}$ was added in very elderly (age $\geq \mathbf{8 0}$ years) patients who do not have diabetes or target organ damage (systolic blood pressure target in this population remains at $<150 \mathrm{~mm} \mathrm{Hg}$ ); and (3) the target population recommended to receive low-dose acetylsalicylic acid therapy for primary prevention was narrowed from all patients with controlled hypertension to only those $\geq 50$ years of age. The 2 new

\section{Executive Summary}

Objective: To provide updated 2014 evidence-based recommendations for the prevention, diagnosis, assessment, and treatment of hypertension in adults.

Methods: A medical librarian independently conducted a MEDLINE search current to August 2013. Reference lists were reviewed and experts were contacted to identify additional studies. Content and methodology experts reviewed and

\section{RÉSUMÉ}

Ici nous présentons en détail les mises à jour des recommandations fondées sur des preuves concernant le diagnostic, l'évaluation, la prévention et le traitement de l'hypertension artérielle des adultes canadiens. Pour l'année 2014, 3 recommandations ont été modifiées et 2 nouvelles recommandations ont été ajoutées. Les recommandations suivantes ont été modifiées : 1) les seuils de l'apport recommandé en sodium sont passés de $\leq 1500 \mathrm{mg}(3,75 \mathrm{~g}$ de sel) à approximativement $2000 \mathrm{mg}$ (5 g de sel) par jour; 2) un seuil de $\geq 160 \mathrm{~mm} \mathrm{Hg}$ pour la pression artérielle systolique au début de la pharmacothérapie a été ajouté pour les patients très âgés ( $\geq 80$ ans) n'ayant pas de diabète ou d'atteinte à un organe cible (les valeurs cibles de pression artérielle systolique chez cette population ont été maintenues à $<150 \mathrm{~mm} \mathrm{Hg}$ ); 3) la population cible devant recevoir le traitement d'acide acétylsalicylique à faible dose pour la prévention

appraised relevant articles using standardized grading algorithms. For pharmacologic interventions, evidence from randomized trials and systematic reviews of trials were preferred and changes in cardiovascular morbidity and mortality, and total mortality, were the primary outcomes of interest. For health behaviour management, blood pressure (BP)-lowering was accepted as a primary outcome. In patients with chronic kidney disease (CKD), progressive renal impairment was 
recommendations are: (1) advice to be cautious when lowering systolic blood pressure to target levels in patients with established coronary artery disease if diastolic blood pressure is $\leq 60 \mathrm{~mm} \mathrm{Hg}$ because of concerns that myocardial ischemia might be exacerbated; and (2) the addition of glycated hemoglobin (A1C) in the diagnostic work-up of patients with newly diagnosed hypertension. The rationale for these recommendation changes is discussed. In addition, emerging data on blood pressure targets in stroke patients are discussed; these data did not lead to recommendation changes at this time. The Canadian Hypertension Education Program recommendations will continue to be updated annually.

accepted as a clinically relevant primary outcome. All recommendations were graded according to the strength of the supporting evidence, and newly proposed recommendations or changes to existing recommendations were discussed at a consensus conference held October 15-16, 2013, in Montreal, Canada. Proposed changes to the recommendations accepted at the consensus conference were subsequently voted on by the 69 members of the Canadian Hypertension Education Program (CHEP) Recommendations Task Force (RTF). Recommendations that received at least $70 \%$ task force approval were accepted as final.

\section{Recommendations}

\section{Diagnosis and assessment}

One new recommendation related to the addition of glycated hemoglobin (A1C) as a diagnostic screening test in newly diagnosed hypertensive patients was added.

\section{Prevention and treatment}

For 2014, 3 existing recommendations were modified and 1 new recommendation was added. Modifications to existing recommendations include: (1) a change in the recommended sodium intake threshold to approximately $2000 \mathrm{mg}$ (5 g of salt) per day from $\leq 1500 \mathrm{mg}$ (3.75 g of salt); (2) the addition of a systolic BP $(\mathrm{SBP}) \geq 160 \mathrm{~mm} \mathrm{Hg}$ pharmacotherapy treatment initiation threshold in very elderly (age $\geq 80$ years) patients who do not have diabetes or target organ damage (with the SBP target in this population remaining at $<150$ $\mathrm{mm} \mathrm{Hg}$ ); and (3) a modification to the target population recommended to receive low-dose acetylsalicylic acid (ASA) therapy for primary prevention from all controlled hypertensive patients to those $\geq 50$ years. The new recommendations include advice to be cautious when lowering SBP to target levels in patients with established coronary artery disease (CAD) if diastolic BP (DBP) is $\leq 60 \mathrm{~mm} \mathrm{Hg}$ because of concerns that myocardial ischemia might be exacerbated.

\section{Updates}

CHEP will continue to update recommendations annually. primaire est passée de tous les patients ayant une hypertension qui est contrôlée à seulement ceux ayant $\geq 50$ ans. Les 2 nouvelles recommandations sont : 1 ) les conseils de prudence lors de la diminution de la pression artérielle systolique aux valeurs cibles chez les patients ayant une coronaropathie établie si la pression artérielle diastolique est $\leq 60 \mathrm{~mm}$ Hg puisque les risques liés à l'ischémie myocardique pourraient être exacerbés; 2) l'ajout de l'hémoglobine glyquée (A1c) au bilan diagnostique des patients ayant nouvellement reçu un diagnostic d'hypertension. Nous discutons des raisons de ces modifications des recommandations. Nous discutons également des nouvelles données sur les valeurs cibles de pression artérielle chez les patients ayant subi un accident vasculaire cérébral; ces données n'ont actuellement pas entraîné de modifications des recommandations. Les recommandations du Programme éducatif canadien sur l'hypertension continueront d'être mises à jour annuellement.

\section{Introduction}

Hypertension affects approximately $20 \%$ of the Canadian adult population ${ }^{1,2}$ and is a major risk factor for cardiovascular disease, $\mathrm{CKD}$, and death, remaining largely silent until the development of complications. ${ }^{3,4}$ Worldwide, high BP affects more than $40 \%$ of adults ${ }^{5}$ and is the leading global risk factor for death or disability. ${ }^{6}$ BP control rates are nearly $65 \%$ in Canada and $13.2 \%$ globally. ${ }^{1,5}$

With the goal of improving hypertension prevention, detection, assessment, and management in Canadian adults, the CHEP, with funding from Hypertension Canada, produces annually updated, evidence-based recommendations for primary care and other health care providers. This document outlines all recommendations endorsed by the CHEP RTF and contains detailed discussion of the evidence base and rationale for recommendations that have been updated or newly added for 2014. Discussion of the rationale for recommendations that remain unchanged is available in previous publications. ${ }^{7-28}$ A full set of supplementary tables are available as an online supplement to this article.

The recommendations detailed herein are intended to guide health care providers and should not replace sound clinical judgement. Practitioners are advised to consider patient preferences when applying these recommendations in the care of their patients and should note that CHEP does not currently take into account economic considerations when formulating recommendations. Although individual antihypertensive agents may be mentioned when discussing evidence, the reader should assume a class effect, unless otherwise stated.

\section{Methods}

The CHEP RTF is a multidisciplinary panel of content and methodological experts comprised of 2 Co-Chairs, a Central Review Committee (CRC), and 23 subgroups. Each subgroup addresses a distinct content area in hypertension (see Supplemental Appendix S1 for the current CHEP membership list). Members of the Canadian Task Force on Preventive Health Care, Canadian Diabetes Association Guidelines Committee, Canadian Society of Nephrology, Canadian Stroke Network, Canadian Cardiovascular Society, and the Canadian Cardiovascular Harmonized National Guideline Endeavour Initiative regularly collaborate with CHEP members to facilitate harmonization of hypertension-related 
recommendations across organizations. In many cases, the CHEP RTF members serve as volunteers for multiple organizations.

Systematic literature searches current to August 2013 were performed by a Cochrane Collaboration librarian in MEDLINE/PubMed using text words and MeSH headings. Search terms included hypertension[MeSH], hypertens* $\left.{ }^{*} \mathrm{ti}, \mathrm{ab}\right]$, and blood pressure; these were combined with topic-specific terms. Bibliographies of identified articles were also manually searched. Details of search strategies and retrieved articles are available on request. Randomized controlled trials and systematic reviews of randomized trials were reviewed for treatment recommendations and cross-sectional and cohort studies were reviewed for assessment of diagnosis and prognosis.

Each subgroup examined the search results pertinent to its content area. Studies that assessed relevant outcomes were selected for further review. Cardiovascular morbidity and mortality and total mortality outcomes were prioritized for pharmacotherapy studies. For health behaviour recommendations, BP was considered an acceptable surrogate and, in patients with CKD, progressive renal impairment was considered to be a clinically important outcome. Study characteristics and study quality were assessed using prespecified, standardized algorithms developed by the $\mathrm{CHEP}^{29}$ for the critical appraisal of randomized controlled trials and cohort studies. Recommendations were graded according to the strength of their underlying evidence (for details, see Supplemental Table S1), ranging from Grade A (strongest evidence, based on highquality studies) to Grade D (weakest evidence, based on low power, imprecise studies, or expert opinion alone). Although the CHEP does not use the Grading of Recommendations Assessment, Development and Evaluation (GRADE) recommendation scheme (www.gradeworkinggroup.org), it should be noted that all CHEP recommendations are considered to be "strong" in nature (ie, the CHEP refrains from making "weak" recommendations). Thus, the CHEP grading scheme refers only to the quality of evidence and not to the relative strength of the recommendation. For pharmacotherapy recommendations, as a general rule, the CHEP considers evidence evaluating specific agents to be generalizable to a "class effect." For diuretic therapy, the term "thiazides" refers to hydrochlorthiazide (or similar agents) and the term "thiazide-like" refers to chlorthalidone and indapamide.

Subgroup members, considered content experts in their fields, were responsible for reviewing annual search results and, if indicated, drafting new recommendations or proposing changes to old recommendations. An independent CRC consisting of methodological experts with no industry affiliations independently reviewed, graded, and refined proposed recommendations, which were then presented at a consensus conference of the RTF in Montreal, Canada on October 16 and 17, 2013. This meeting included the Co-Chairs, CRC, and members of all subgroups. Further revisions to the proposed recommendations were based on these discussions.

After the consensus meeting, the recommendations were finalized and submitted electronically to all 69 voting members of the CHEP RTF for approval. Members with potential conflicts of interest recused themselves from voting on specific recommendations (a list of conflicts is in Supplemental Appendix S2). Recommendations receiving $>70 \%$ approval passed. The CHEP recommendations process is in accordance with the AGREE II guidelines ${ }^{30}$ and has been externally reviewed. A summary of how the CHEP process aligns with Appraisal of Guidelines, Research and Evaluation (AGREE) II may be found online at: http://www.hypertension.ca/en/chep/ overview-a-process agree. Materials to assist with patient and public education based on these recommendations are freely available at: http://www.hypertension.ca.

\section{The 2014 CHEP Diagnosis and Assessment Recommendations}

\section{Accurate measurement of BP}

\section{Recommendations}

1. Health care professionals who have been specifically trained to measure BP accurately should assess BP in all adult patients at all appropriate visits to determine cardiovascular risk and monitor antihypertensive treatment (Grade D).

2. Use of standardized measurement techniques (Supplemental Table S2) is recommended when assessing BP (Grade D).

3. Automated office BP measurement (OBPM) can be used in the assessment of office BP (Grade D).

4. When used in proper conditions, automated office SBP of $\geq 135 \mathrm{~mm} \mathrm{Hg}$ or DBP of $\geq 85 \mathrm{~mm} \mathrm{Hg}$ should be considered analogous to mean awake ambulatory SBP of $\geq 135 \mathrm{~mm} \mathrm{Hg}$ and DBP of $\geq 85 \mathrm{~mm} \mathrm{Hg}$, respectively (Grade D).

Background. There are no changes to these recommendations for 2014.

\section{Criteria for diagnosis of hypertension and recommendations for follow-up (Fig. 1)}

\section{Recommendations}

1. At initial presentation, patients demonstrating features of a hypertensive urgency or emergency (Supplemental Table S3) should be diagnosed as hypertensive and require immediate management (Grade $\mathrm{D})$.

2. If $\mathrm{SBP}$ is $\geq 140 \mathrm{~mm} \mathrm{Hg}$ and/or DBP is $\geq 90 \mathrm{~mm} \mathrm{Hg}$, a specific visit should be scheduled for the assessment of hypertension (Grade D). If BP is high-normal (SBP 130$139 \mathrm{~mm} \mathrm{Hg}$ and/or DBP 85-89 mm Hg), annual followup is recommended (Grade $\mathrm{C}$ ).

3. At the initial visit for the assessment of hypertension, if $\mathrm{SBP}$ is $\geq 140$ and/or DBP is $\geq 90 \mathrm{~mm} \mathrm{Hg}$, at least 2 more readings should be taken during the same visit using a validated device and according to the recommended procedure for accurate BP determination (Supplemental Table S2). The first reading should be discarded and the latter 2 or more readings averaged. A history and physical examination should be performed and, if clinically indicated, diagnostic tests to search for target organ damage (Supplemental Table S4) and associated cardiovascular risk factors (Supplemental Table S5) should be arranged within 2 visits. Exogenous factors that can induce or aggravate hypertension should be identified and addressed if possible (Supplemental Table S6). Visit 2 should be scheduled within 1 month (Grade D). 


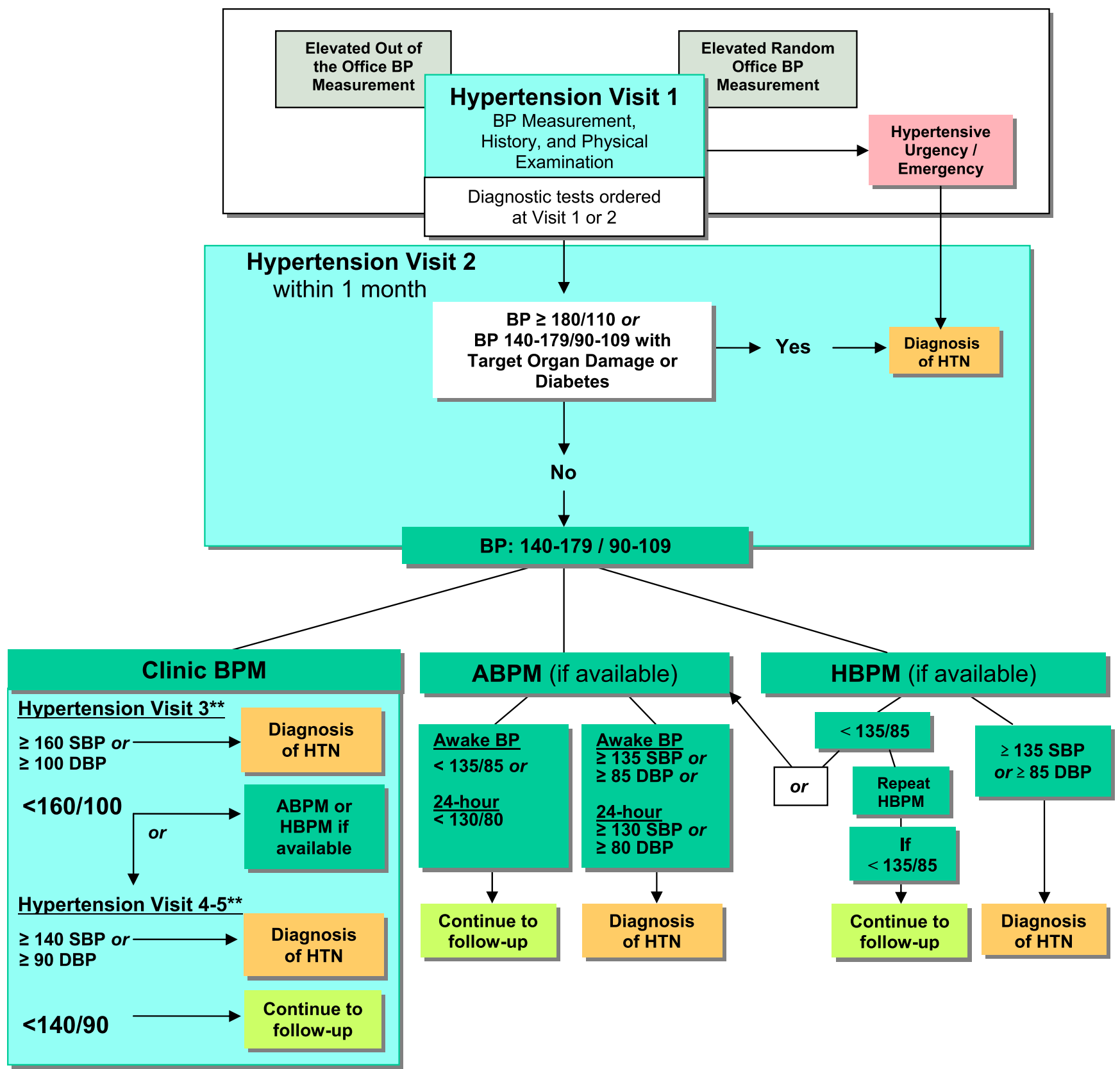

Figure 1. The expedited assessment and diagnosis of patients with hypertension: Focus on validated technologies for BP assessment. ** Thresholds refer to BP values averaged across the corresponding number of visits and not just the most recent office visit. ABPM, ambulatory BP monitoring; BP, blood pressure ( $\mathrm{mm} \mathrm{Hg})$; DBP, diastolic BP $(\mathrm{mm} \mathrm{Hg})$; HBPM, home BP measurement; HTN, hypertension; OBPM, office BP measurement; SBP, systolic BP ( $\mathrm{mm} \mathrm{Hg})$. Reproduced with permission from the Canadian Hypertension Education Program.

4. At visit 2 for the assessment of hypertension, patients with macrovascular target organ damage, diabetes mellitus, or CKD (glomerular filtration rate $<60 \mathrm{~mL} / \mathrm{min} / 1.73 \mathrm{~m}^{2}$ ) can be diagnosed as hypertensive if SBP is $\geq 140 \mathrm{~mm} \mathrm{Hg}$ and/or DBP is $\geq 90 \mathrm{~mm} \mathrm{Hg}$ (Grade D).

5. At visit 2 for the assessment of hypertension, patients without macrovascular target organ damage, diabetes mellitus, or CKD can be diagnosed as hypertensive if the $\mathrm{SBP}$ is $\geq 180 \mathrm{~mm} \mathrm{Hg}$ and/or the DBP is $\geq 110 \mathrm{~mm} \mathrm{Hg}$ (Grade D). Patients without macrovascular target organ damage, diabetes mellitus, or CKD but with lower BP levels should undergo further evaluation using any of the 3 approaches outlined next:

i. OBPM: Using manual OBPM, patients can be diagnosed as hypertensive if the SBP is $\geq 160 \mathrm{~mm} \mathrm{Hg}$ or the DBP is $\geq 100 \mathrm{~mm} \mathrm{Hg}$ averaged across the first 3 visits, or if the SBP averages $\geq 140 \mathrm{~mm} \mathrm{Hg}$ or the DBP averages $\geq 90 \mathrm{~mm} \mathrm{Hg}$ averaged across 5 visits (Grade D).

ii. Ambulatory BP monitoring (ABPM): Using ABPM (see Recommendations in section VIII. ABPM), patients can be diagnosed as hypertensive if the mean awake SBP is $\geq 135 \mathrm{~mm} \mathrm{Hg}$ or the DBP is 
$\geq 85 \mathrm{~mm} \mathrm{Hg}$ or if the mean 24-hour SBP is $\geq 130$ $\mathrm{mm} \mathrm{Hg}$ or the DBP is $\geq 80 \mathrm{~mm} \mathrm{Hg}$ (Grade C).

iii. Home BP monitoring (HBPM): Using HBPM (see Recommendations in section VII. HBPM), patients can be diagnosed as hypertensive if the average SBP is $\geq 135 \mathrm{~mm} \mathrm{Hg}$ or the DBP is $\geq 85 \mathrm{~mm} \mathrm{Hg}$ (Grade C). If the average home $\mathrm{BP}$ is $<135 / 85 \mathrm{~mm} \mathrm{Hg}$, it is advisable to either repeat home monitoring to confirm the home $\mathrm{BP}$ is $<135 / 85 \mathrm{~mm} \mathrm{Hg}$ or perform 24-hour $\mathrm{ABPM}$ to confirm that the mean 24-hour ABPM is $<130 / 80 \mathrm{~mm} \mathrm{Hg}$ and the mean awake ABPM is $<135 / 85 \mathrm{~mm} \mathrm{Hg}$ before diagnosing white coat hypertension (Grade D).

6. Investigations for secondary causes of hypertension should be initiated in patients with suggestive clinical and/or laboratory features (outlined in sections $V$. Assessment for Renovascular Hypertension and VI. Endocrine Hypertension) (Grade D).

7. If, at the last diagnostic visit, the patient is not diagnosed as hypertensive and has no evidence of macrovascular target organ damage, the patient's BP should be assessed at yearly intervals (Grade D).

8. Hypertensive patients actively modifying their health behaviours should be followed up at 3- to 6-month intervals. Shorter intervals (every 1 or 2 months) are needed for patients with higher BP measurements (Grade D).

9. Patients using antihypertensive drugs should be seen monthly or every 2 months, depending on the level of BP, until readings on 2 consecutive visits are below their target (Grade D). Shorter intervals between visits will be needed for symptomatic patients and those with severe hypertension, intolerance to antihypertensive drugs, or target organ damage (Grade D). When the target BP has been reached, patients should be seen at 3- to 6-month intervals (Grade D).

Background. There are no changes to these recommendations for 2014.

\section{Assessment of overall cardiovascular risk in hypertensive patients}

\section{Recommendations}

1. Global cardiovascular risk should be assessed. Multifactorial risk assessment models can be used to predict more accurately an individual's global cardiovascular risk (Grade A) and to use antihypertensive therapy more efficiently (Grade D). In the absence of Canadian data to determine the accuracy of risk calculations, avoid using absolute levels of risk to support treatment decisions (Grade C).

2. Consider informing patients of their global risk to improve the effectiveness of risk factor modification (Grade B). Consider also using analogies that describe comparative risk such as "cardiovascular age," "vascular age," or "heart age" to inform patients of their risk status (Grade B).

Background. There are no changes to these recommendations for 2014. Risk calculators are freely available at: www. myhealthcheckup.com (www.monbilansante.com) and www. score-canada.ca. The latter Web site is the Systematic Cerebrovascular and Coronary Risk Evaluation [SCORE]) risk calculator. Although no risk engine developed from Canadian data exists, Canadian cardiovascular disease prevalence and mortality risk have been integrated into the original SCORE risk engine to produce specific estimates for the Canadian population (SCORE Canada).

\section{Routine and optional laboratory tests for the investigation of patients with hypertension}

\section{Recommendations}

1. Routine laboratory tests that should be performed for the investigation of all patients with hypertension include the following:

i. Urinalysis (Grade D);

ii. Blood chemistry (potassium, sodium, and creatinine) (Grade D);

iii. Fasting blood glucose and/or glycated hemoglobin (A1C) (Grade D) (new recommendation);

iv. Fasting serum total cholesterol, high-density lipoprotein cholesterol, low-density lipoprotein cholesterol, and triglycerides (Grade D); and

v. Standard 12-lead electrocardiography (Grade C).

2. Assess urinary albumin excretion in patients with diabetes (Grade D).

3. All treated hypertensive patients should be monitored according to the current Canadian Diabetes Association guidelines for the new appearance of diabetes (Grade B).

4. During the maintenance phase of hypertension management, tests (including those for electrolyte, creatinine, and fasting lipid levels) should be repeated with a frequency reflecting the clinical situation (Grade D).

Background. When compared with oral glucose tolerance testing, a systematic review suggests that $\mathrm{A} 1 \mathrm{C}$ and fasting glucose levels demonstrate comparable sensitivity and specificity for diabetes detection. ${ }^{31}$ In a more recent analysis of more than 2000 adults at high risk for diabetes, $\mathrm{Hu}$ and colleagues determined the sensitivity and specificity for diabetes of A1C and fasting glucose to be virtually identical at the thresholds evaluated. In addition, when both tests were combined, sensitivity $(96.5 \%)$ and specificity $(96.3 \%)$ increased. ${ }^{32}$ The addition of A1C harmonizes the CHEP recommendations with those of the Canadian Diabetes Association. ${ }^{33}$

\section{Assessment for renovascular hypertension}

\section{$\underline{\text { Recommendations }}$}

1. Patients presenting with $\geq 2$ of the clinical clues listed below, suggesting renovascular hypertension, should be investigated (Grade D):

i. Sudden onset or worsening of hypertension and age $>$ 55 or $<30$ years;

ii. Presence of an abdominal bruit;

iii. Hypertension resistant to $\geq 3$ drugs;

iv. Increase in serum creatinine level $\geq 30 \%$ associated with use of an angiotensin-converting enzyme (ACE) inhibitor or angiotensin receptor blocker (ARB);

v. Other atherosclerotic vascular disease, particularly in patients who smoke or have dyslipidemia; 
vi. Recurrent pulmonary edema associated with hypertensive surges.

2. When available, the following tests are recommended to aid in the usual screening for renal vascular disease: captoprilenhanced radioisotope renal scan, Doppler sonography, magnetic resonance angiography, and computed tomography angiography (for those with normal renal function) (Grade B). Captopril-enhanced radioisotope renal scan is not recommended for those with CKD (glomerular filtration rate $\left.<60 \mathrm{~mL} / \mathrm{min} / 1.73 \mathrm{~m}^{2}\right)$ (Grade D).

Background. There are no changes to these recommendations for 2014.

\section{Endocrine hypertension}

\section{Recommendations}

\section{A. Hyperaldosteronism: screening and diagnosis}

1. Screening for hyperaldosteronism should be considered for the following patients (Grade D):

i. Hypertensive patients with spontaneous hypokalemia $\left(\mathrm{K}^{+}<3.5 \mathrm{mmol} / \mathrm{L}\right)$;

ii. Hypertensive patients with marked diureticinduced hypokalemia $\left(\mathrm{K}^{+}<3.0 \mathrm{mmol} / \mathrm{L}\right)$;

iii. Patients with hypertension refractory to treatment with $\geq 3$ drugs;

iv. Hypertensive patients found to have an incidental adrenal adenoma.

2. Screening for hyperaldosteronism should include assessment of plasma aldosterone and plasma renin activity or plasma renin (Supplemental Table S7).

3. For patients with suspected hyperaldosteronism (on the basis of the screening test; Supplemental Table S7, item iii. Definition of a Positive Screening Test), a diagnosis of primary aldosteronism should be established by demonstrating inappropriate autonomous hypersecretion of aldosterone using at least 1 of the manoeuvres listed in Supplemental Table S7, item iv. Manoeuvres to demonstrate Autonomous Hypersecretion of Aldosterone. When the diagnosis is established, the abnormality should be localized using any of the tests described in Supplemental Table S7, item $v$. Differentiating Potential Causes of Primary Aldosteronism.

\section{B. Pheochromocytoma: screening and diagnosis}

1. If pheochromocytoma is strongly suspected, the patient should be referred to a specialized hypertension centre, particularly if biochemical screening tests (Supplemental Table S8) have already been found to be positive (Grade D).

2. The following patients should be considered for screening for pheochromocytoma (Grade D):

i. Patients with paroxysmal and/or severe (BP $\geq 180$ / $110 \mathrm{~mm} \mathrm{Hg}$ ) sustained hypertension refractory to usual antihypertensive therapy;

ii. Patients with hypertension and multiple symptoms suggestive of catecholamine excess (eg, headaches, palpitations, sweating, panic attacks, and pallor);

iii. Patients with hypertension triggered by $\beta$-blockers, monoamine oxidase inhibitors, micturition, or changes in abdominal pressure; iv. Patients with incidentally discovered adrenal mass and patients with hypertension and multiple endocrine neoplasia $2 \mathrm{~A}$ or $2 \mathrm{~B}$, von Recklinghausen neurofibromatosis, or von Hippel-Lindau disease;

v. For patients with positive biochemical screening tests, localization of pheochromocytomas should involve the use of magnetic resonance imaging (preferable), computed tomography (if magnetic resonance imaging is unavailable), and/or iodine I-131 metaiodobenzylguanidine scintigraphy (Grade C for each modality).

Background. There are no changes to these recommendations for 2014.

\section{HBPM}

\section{Recommendations}

1. HBPM can be used in the diagnosis of hypertension (Grade C).

2. The use of HBPM on a regular basis should be considered for patients with hypertension, particularly those with:

i. Diabetes mellitus (Grade D);

ii. CKD (Grade C);

iii. Suspected nonadherence (Grade D);

iv. Demonstrated white coat effect (Grade C); or

v. BP controlled in the office but not at home (masked hypertension) (Grade C).

3. When white coat hypertension is suggested by HBPM, its presence should be confirmed by repeat HBPM (see Recommendation 8 in this section) or ABPM before treatment decisions are made (Grade D).

4. Patients should be advised to purchase and use only HBPM devices that are appropriate for the individual and have met standards of the Association for the Advancement of Medical Instrumentation, the most recent requirements of the British Hypertension Society protocol, or the International Protocol for validation of automated BP-measuring devices. Patients should be encouraged to use devices with data recording capabilities or automatic data transmission to increase the reliability of reported HBPM (Grade D).

5 . Home SBP values $\geq 135 \mathrm{~mm} \mathrm{Hg}$ or DBP values $\geq 85 \mathrm{~mm}$ $\mathrm{Hg}$ should be considered increased and associated with an increased overall mortality risk analogous to office SBP readings of $\geq 140 \mathrm{~mm} \mathrm{Hg}$ or DBP $\geq 90 \mathrm{~mm} \mathrm{Hg}$ (Grade C).

6. Health care professionals should ensure that patients who measure their BP at home have adequate training and, if necessary, repeat training in measuring their BP. Patients should be observed to determine that they measure BP correctly and should be given adequate information about interpreting these readings (Grade D).

7. The accuracy of all individual patients' validated devices (including electronic devices) must be regularly checked against a device of known calibration (Grade D).

8. HBPM for assessing white coat hypertension or sustained hypertension should be based on duplicate measures, morning and evening, for an initial 7-day period. First-day home BP values should not be considered (Grade D).

Background. There are no changes to these recommendations for 2014. 


\section{ABPM}

\section{Recommendations}

1. ABPM can be used in the diagnosis of hypertension (Grade C). ABPM should be considered when an office-induced increase in BP is suspected in treated patients with:

i. BP that is not below target despite receiving appropriate chronic antihypertensive therapy (Grade C);

ii. Symptoms suggestive of hypotension (Grade C); or iii. Fluctuating office BP readings (Grade D).

2. Physicians should use only ABPM devices that have been validated independently using established protocols (Grade D).

3. Therapy adjustment should be considered in patients with a mean 24-hour ambulatory SBP of $\geq 130 \mathrm{~mm} \mathrm{Hg}$ or DBP of $\geq 80 \mathrm{~mm} \mathrm{Hg}$ or a mean awake SBP of $\geq 135 \mathrm{~mm}$ $\mathrm{Hg}$ or DBP of $\geq 85 \mathrm{~mm} \mathrm{Hg}$ (Grade D).

4. The magnitude of changes in nocturnal BP should be taken into account in any decision to prescribe or withhold drug therapy based on ABPM (Grade C) because a decrease in nocturnal $\mathrm{BP}$ of $<10 \%$ is associated with increased risk of cardiovascular events.

Background. There are no changes to these recommendations for 2014.

\section{Role of echocardiography}

\section{Recommendations}

1. Routine echocardiographic evaluation of all hypertensive patients is not recommended (Grade D).

2. An echocardiogram for assessment of left ventricular hypertrophy is useful in selected cases to help define the future risk of cardiovascular events (Grade C).

3. Echocardiographic assessment of left ventricular mass, and of systolic and diastolic left ventricular function is recommended for hypertensive patients suspected to have left ventricular dysfunction or CAD (Grade D).

4. Patients with hypertension and evidence of heart failure should have an objective assessment of left ventricular ejection fraction, either using echocardiogram or nuclear imaging (Grade D).

Background. There are no changes to these recommendations for 2014.

\section{The CHEP 2014 Prevention and Treatment Recommendations}

Please note that treatment thresholds and targets refer to OBPM. Please refer to section II. Criteria for Diagnosis of Hypertension and Recommendations for Follow-up, for corresponding values of other measurement methods.

\section{Health behaviour management}

\section{Recommendations}

\section{A. Physical exercise}

1. For nonhypertensive or stage 1 hypertensive individuals, the use of resistance or weight training exercise (such as free weight lifting, fixed weight lifting, or handgrip exercise) does not adversely influence BP (Grade D). For nonhypertensive individuals (to reduce the possibility of becoming hypertensive) or for hypertensive patients (to reduce their $\mathrm{BP}$ ), prescribe the accumulation of 30-60 minutes of moderate intensity dynamic exercise (eg, walking, jogging, cycling, or swimming) 4-7 days per week in addition to the routine activities of daily living (Grade D). Higher intensities of exercise are not more effective (Grade D).

\section{B. Weight reduction}

1. Height, weight, and waist circumference should be measured and body mass index calculated for all adults (Grade D).

2. Maintenance of a healthy body weight (body mass index of 18.5 to 24.9 , and waist circumference $<102 \mathrm{~cm}$ for men and $<88 \mathrm{~cm}$ for women) is recommended for nonhypertensive individuals to prevent hypertension (Grade C) and for hypertensive patients to reduce BP (Grade B). All overweight hypertensive individuals should be advised to lose weight (Grade B).

3. Weight loss strategies should use a multidisciplinary approach that includes dietary education, increased physical activity, and behavioural intervention (Grade B).

\section{Alcohol consumption}

1. To reduce $\mathrm{BP}$, alcohol consumption should be in accordance with Canadian low-risk drinking guidelines in normotensive and hypertensive individuals. Healthy adults should limit alcohol consumption to $\leq 2$ drinks per day, and consumption should not exceed 14 standard drinks per week for men and 9 standard drinks per week for women (Grade B). (Note: One standard drink is considered to be equivalent to $13.6 \mathrm{~g}$ or $17.2 \mathrm{~mL}$ of ethanol or approximately $44 \mathrm{~mL}[1.5 \mathrm{oz}]$ of 80 proof [40\%] spirits, $355 \mathrm{~mL}[12 \mathrm{oz}]$ of $5 \%$ beer, or $148 \mathrm{~mL}$ [5 oz] of $12 \%$ wine.)

D. Dietary recommendations

1. It is recommended that hypertensive patients and normotensive individuals at increased risk of developing hypertension consume a diet that emphasizes fruits, vegetables, low-fat dairy products, dietary and soluble fibre, whole grains, and protein from plant sources that is reduced in saturated fat and cholesterol (Dietary Approaches to Stop Hypertension [DASH] $\operatorname{diet}^{34-37}$; Supplemental Table S9) (Grade B).

\section{E. Sodium intake}

1. To decrease BP, consider reducing sodium intake toward $2000 \mathrm{mg}$ ( $5 \mathrm{~g}$ of salt or $87 \mathrm{mmol}$ of sodium) per day (Grade A) (revised recommendation).

F. Potassium, calcium, and magnesium intake

1. Supplementation of potassium, calcium, and magnesium is not recommended for the prevention or treatment of hypertension (Grade B).

\section{G. Stress management}

1. In hypertensive patients in whom stress might be a contributor to high BP, stress management should be considered as an intervention (Grade D). Individualized cognitive-behavioural interventions are more likely to be effective when relaxation techniques are used (Grade B). 
Background. The revised recommendation, which increases the target sodium threshold from $\leq 1500 \mathrm{mg} / \mathrm{d}$, is primarily based on clinical trial evidence from 2 systematic reviews published in 2013. ${ }^{38,39}$ The evidence focuses on BP as a surrogate end point. The RTF noted the inconclusive nature of the data examining morbidity and mortality end points and awaits the results of further studies examining these end points. ${ }^{40}$

He and colleagues ${ }^{38}$ examined 22 crossover and parallelarm randomized controlled trials that enrolled 999 hypertensive individuals and compared reduced salt intake with usual salt intake over a period of 4-52 weeks. Studies documenting a 40-120 mmol reduction in 24-hour urine sodium (equivalent to $920-2760 \mathrm{mg}$ of sodium or 2.3-7 g of salt) were included. The median baseline BP was 148/93 $\mathrm{mm} \mathrm{Hg}$ and the median baseline 24-hour urine sodium excretion was $162 \mathrm{mmol}$ (range, 125-191 mmol). The pooled estimated reduction in sodium intake between usual intake and reduced intake was $75 \mathrm{mmol}$ per 24 hours $(95 \%$ confidence interval [CI], 53-117). Therefore, from baseline levels in the usual care arm, interventions reduced sodium intake toward a threshold of $87 \mathrm{mmol}$ (ie, $162-75 \mathrm{mmol}$ ) or $2000 \mathrm{mg}$ per day. Reduced intake led to a $5.39 \mathrm{~mm} \mathrm{Hg}$ reduction $(95 \% \mathrm{CI}, 4.15-6.62)$ in $\mathrm{SBP}$ and a $2.82 \mathrm{~mm} \mathrm{Hg}$ reduction (95\% CI, 2.11-3.54) in DBP (pooled mean effects).

The systematic review by Aburto and colleagues ${ }^{39}$ was conducted on behalf of the World Health Organization Nutrition Guidance Expert Advisory Group Subgroup on Diet and Health. In 36 randomized controlled trials that enrolled 5508 participants overall and 1478 subjects with hypertension, a reduction in sodium intake resulted in a mean $3.39 \mathrm{~mm} \mathrm{Hg}$ reduction (95\% CI, 2.46-4.31 $\mathrm{mm} \mathrm{Hg}$ ) in SBP in all subjects and a $4.06 \mathrm{~mm} \mathrm{Hg} \mathrm{SBP}$ reduction $(95 \% \mathrm{CI}$, 2.96-5.15) in the subgroup with hypertension. A subgroup analysis indicated that a reduction in sodium intake to less than $2000 \mathrm{mg} / \mathrm{d}$ led to a decrease in SBP of $3.47 \mathrm{~mm} \mathrm{Hg}$ (95\% CI, 0.76-6.18). Concurrent use of antihypertensive medication did not appear to diminish the effect of decreasing sodium intake.

\section{Indications for drug therapy for adults with hypertension without compelling indications for specific agents}

\section{Recommendations}

1. Antihypertensive therapy should be prescribed for average DBP measurements of $\geq 100 \mathrm{~mm} \mathrm{Hg}$ (Grade A) or average SBP measurements of $\geq 160 \mathrm{~mm} \mathrm{Hg}$ (Grade A) in patients without macrovascular target organ damage or other cardiovascular risk factors.

2. Antihypertensive therapy should be strongly considered if DBP readings average $\geq 90 \mathrm{~mm} \mathrm{Hg}$ in the presence of macrovascular target organ damage or other independent cardiovascular risk factors (Grade A).

3. Antihypertensive therapy should be strongly considered if SBP readings average $\geq 140 \mathrm{~mm} \mathrm{Hg}$ in the presence of macrovascular target organ damage (Grade $\mathrm{C}$ for 140-160 $\mathrm{mm} \mathrm{Hg}$; Grade A for $>160 \mathrm{~mm} \mathrm{Hg}$ ).
4. Antihypertensive therapy should be considered in all patients meeting indications 1-3 in this section, regardless of age (Grade B). Caution should be exercised in elderly patients who are frail.

5. In the very elderly (age $\geq 80$ years) patients who do not have diabetes or target organ damage, the SBP threshold for initiating drug therapy is $\geq 160 \mathrm{~mm} \mathrm{Hg}$ (Grade C) (revised recommendation).

Background. In 2013, CHEP introduced a $<150 \mathrm{~mm} \mathrm{Hg}$ SBP treatment target for adults 80 years of age or older (see Recommendation 2 in section $V$. Goals of Therapy for Adults With Hypertension Without Compelling Indications for Specific Agents). This year, a $\geq 160 \mathrm{~mm} \mathrm{Hg}$ pharmacotherapy treatment initiation threshold was added. This recommendation was based on data from the Hypertension in the Very Elderly Trial (HYVET) ${ }^{41,42}$ and a meta-analysis by Gueyffier and colleagues. ${ }^{43}$ The HYVET enrolled 3845 hypertensive adults (defined as SBP of $\geq 160 \mathrm{~mm} \mathrm{Hg}$ ) aged 80 years or older and randomized to active vs placebo treatment in which the active treatment arm received indapamide $1.5 \mathrm{mg}$ with or without perindopril $(2-4 \mathrm{mg})$ to achieve a target $\mathrm{BP}$ of $<150 / 80 \mathrm{~mm}$ $\mathrm{Hg}$. The primary outcome of the trial was stroke (fatal and nonfatal), with all-cause mortality a predefined secondary outcome. The trial was stopped early (median follow-up was 1.8 years) when a planned interim analysis demonstrated active treatment to be associated with a lower risk of stroke (hazard ratio [HR], 0.59; 95\% CI, 0.40-0.88) and all-cause mortality (HR, 0.76; 95\% CI, 0.62-0.93). However, the final time-to-event analysis, completed after the trial was stopped and all end points had been counted, ${ }^{41}$ revealed that the active treatment effect was no longer conclusive with respect to stroke (HR, 0.70;95\% CI, 0.49-1.01), but that there was still a conclusive $21 \%$ reduction in the risk of allcause mortality (HR, 0.79; 95\% CI, 0.65-0.95). The CHEP thus continues to recommend an SBP treatment target of $<150 \mathrm{~mm} \mathrm{Hg}$, but in line with HYVET procedures, the SBP threshold for the initiation of treatment is now specified as $160 \mathrm{~mm} \mathrm{Hg}$. As noted in the 2013 CHEP recommendations, the HYVET population had low rates of comorbid disease and adverse events during treatment. Subjects with orthostatic hypotension were likely excluded because standing SBP had to be $\geq 140 \mathrm{~mm} \mathrm{Hg}$ at the last visit before randomization. Therefore the RTF continues to recommend caution when applying this recommendation to frail elderly patients. For patients with SBP of 150-160 mm $\mathrm{Hg}$, providers should exercise clinical judgement when deciding whether to initiate drug treatment and should note that nonpharmacological therapy is still indicated for all patients.

Further support for the $\geq 160 \mathrm{~mm} \mathrm{Hg} \mathrm{SBP}$ pharmacologic treatment threshold in the very elderly population comes from the pre-HYVET meta-analysis by Gueyffier and colleagues, ${ }^{43}$ evaluating the efficacy of hypertension treatment in patients $\geq 80$ years of age. These investigators included data from 7 trials that compared the efficacy of active treatment with either placebo, no treatment, or decreased doses of active treatment on the primary outcome of fatal and nonfatal stroke. Five of the 7 trials enrolled patients with SBP levels $\geq 160 \mathrm{~mm} \mathrm{Hg}$. Among participants 
randomized to active treatment $(\mathrm{n}=874)$, there were 57 strokes and 34 stroke deaths, compared with 77 strokes and 28 stroke deaths among participants randomized to the comparator groups $(\mathrm{n}=796)$. The risk for stroke was $34 \%$ less (relative risk, 0.66; 95\% CI, 0.48-0.92) among those in the active treatment arms. Taken together, this meta-analysis $^{43}$ and HYVET $^{41,42}$ provide evidence that treatment initiated at a threshold of $\geq 160 \mathrm{~mm} \mathrm{Hg}$ reduces cardiovascular events and all-cause mortality in elderly patients.

\section{Choice of therapy for adults with hypertension without compelling indications for specific agents}

\section{Recommendations}

\section{A. Recommendations for individuals with diastolic and/or systolic hypertension}

1. Initial therapy should be a single-agent thiazide/thiazide-like diuretic (Grade A), a $\beta$-blocker (in patients younger than 60 years; Grade B), an ACE inhibitor (in non-black patients; Grade B), a long-acting calcium channel blocker (CCB) (Grade B); or an ARB (Grade B). If there are adverse effects, another drug from this group should be substituted. Hypokalemia should be avoided in patients treated with thiazide/thiazide-like diuretic monotherapy (Grade C).

2. Additional antihypertensive drugs should be used if target BP levels are not achieved with standard-dose monotherapy (Grade B). Add-on drugs should be chosen from first-line choices. Useful choices include a thiazide/thiazide-like diuretic or CCB with either: ACE inhibitor, ARB or $\beta$-blocker (Grade B for the combination of thiazide/thiazide-like diuretic and a dihydropyridine CCB; Grade $\mathrm{C}$ for the combination of dihydropyridine CCB and ACE inhibitor; and Grade D for all other combinations). Caution should be exercised in combining a nondihydropyridine $\mathrm{CCB}$ and a $\beta$-blocker (Grade D). The combination of an ACE inhibitor and an ARB is not recommended (Grade A).

3. Combination therapy using 2 first-line agents might also be considered as initial treatment of hypertension (Grade C) if SBP is $20 \mathrm{~mm} \mathrm{Hg}$ greater than target or if $\mathrm{DBP}$ is $10 \mathrm{~mm} \mathrm{Hg}$ greater than target. However, caution should be exercised in patients in whom a substantial decrease in BP from initial combination therapy is more likely to occur or in whom it would be poorly tolerated (eg, elderly patients).

4. If $\mathrm{BP}$ is still not controlled with a combination of 2 or more first-line agents, or there are adverse effects, other antihypertensive drugs may be added (Grade D).

5. Possible reasons for poor response to therapy (Supplemental Table S10) should be considered (Grade D).

6. $\alpha$-Blockers are not recommended as first-line agents for uncomplicated hypertension (Grade A); $\beta$-blockers are not recommended as first-line therapy for uncomplicated hypertension in patients 60 years of age or older (Grade A); and ACE inhibitors are not recommended as first-line therapy for uncomplicated hypertension in black patients (Grade A). However, these agents may be used in patients with certain comorbid conditions or in combination therapy.
Background. There are no changes to these recommendations for 2014.

\section{B. Recommendations for individuals with isolated systolic hypertension}

1. Initial therapy should be single-agent therapy with a thiazide/thiazide-like diuretic (Grade A), a long-acting dihydropyridine CCB (Grade A), or an ARB (Grade $B)$. If there are adverse effects, another drug from this group should be substituted. Hypokalemia should be avoided in patients treated with thiazide/thiazide-like diuretic monotherapy (Grade C).

2. Additional antihypertensive drugs should be used if target BP levels are not achieved with standard-dose monotherapy (Grade B). Add-on drugs should be chosen from first-line options (Grade D).

3. If BP is still not controlled with a combination of 2 or more first-line agents, or there are adverse effects, other classes of drugs (such as $\boldsymbol{\alpha}$-blockers, ACE inhibitors, centrally acting agents, or nondihydropyridine CCBs) may be added or substituted (Grade D).

4. Possible reasons for poor response to therapy (Supplemental Table S10) should be considered (Grade D).

5. $\boldsymbol{\alpha}$-Blockers are not recommended as first-line agents for uncomplicated isolated systolic hypertension (Grade A); and $\beta$-blockers are not recommended as first-line therapy for isolated systolic hypertension in patients aged $\geq 60$ years (Grade $A$ ). However, both agents may be used in patients with certain comorbid conditions or in combination therapy.

Background. The recommendation addressing BP targets in the very elderly (age $\geq 80$ years) patients who do not have diabetes or target organ damage has been moved from section II. Choice of Therapy for Adults With Hypertension Without Compelling Indications for Specific Agents; B. Recommendations for Individuals With Isolated Systolic Hypertension to section II. Indications for Drug Therapy for Adults With Hypertension Without Compelling Indications for Specific Agents, because it does not refer to choice of therapy but rather thresholds for initiation of therapy.

\section{Global vascular protection therapy for adults with hypertension without compelling indications for specific agents}

\section{$\underline{\text { Recommendations }}$}

1. Statin therapy is recommended in hypertensive patients with 3 or more cardiovascular risk factors as defined in Supplemental Table S11 (Grade A in patients $>40$ years) or with established atherosclerotic disease (Grade A regardless of age).

2. Consideration should be given to the addition of low-dose ASA therapy in hypertensive patients $\geq 50$ years (Grade B) (revised recommendation). Caution should be exercised if $\mathrm{BP}$ is not controlled (Grade C).

Background. The recommendation to consider ASA for the primary prevention of cardiovascular disease in hypertensive 
patients is based primarily on the Hypertension Optimal Trial (HOT). ${ }^{44}$ In this trial, 18,790 patients aged 50-80 years (mean age, $61.5 \pm 7.5$ years) with DBP levels between 100 and $115 \mathrm{~mm} \mathrm{Hg}$ were randomized using a $3 \times 2$ factorial design to 1 of 3 DBP targets $(\leq 90$ vs $\leq 85$ vs $\leq 80$ $\mathrm{mm} \mathrm{Hg}$ ) and to ASA vs placebo. Over a mean follow-up time of 3.8 years, ASA therapy reduced the incidence of major cardiovascular events (MACE) from $10.5 \%$ to $8.9 \%$ (HR, $0.85 ; 95 \% \mathrm{CI}, 0.73-0.99)$. When silent myocardial infarctions were included in the MACE end point, the overall results were inconclusive (HR, 0.91; 95\% CI, 0.79-1.04). ${ }^{44}$ It is unclear if silent infarctions were an a priori component of the primary end point. On rereview of the trial and protocol, ${ }^{45}$ the recommendation to give low-dose ASA in hypertensive patients was downgraded to Grade B because of this uncertainty.

A second alteration was made to the recommendation. Previously, the RTF recommended that ASA treatment be considered in all hypertensive individuals, with a Grade A rating for those 50 years of age or older. ${ }^{28}$ This year, the recommendation has been modified such that it is restricted to hypertensive patients $\geq 50$ years of age and is more consistent with the population included in the HOT trial. This change also took into consideration the benefits of ASA therapy in terms of reductions in MACE and prevention of cancer and ASA-associated bleeding risks. ${ }^{46,47}$ The RTF did not conduct in-depth modelling of these factors, which are beyond the scope of CHEP's mandate, but did note that an age threshold of 50 years was consistent with the recommendations of other organizations that have performed such analyses. $^{46,48}$

\section{Goals of therapy for adults with hypertension without compelling indications for specific agents}

\section{$\underline{\text { Recommendations }}$}

1. The SBP treatment goal is a pressure level of $<140 \mathrm{~mm}$ $\mathrm{Hg}$ (Grade C). The DBP treatment goal is a pressure level of $<90 \mathrm{~mm} \mathrm{Hg}$ (Grade A).

2 . In the very elderly (age 80 years or greater), the BP target is $<150 \mathrm{~mm} \mathrm{Hg}$ (Grade C).

Background. There are no changes to these recommendations for 2014. Recommendation V.2, which previously appeared as Recommendation III.B.1, has been moved to this section.

\section{Treatment of hypertension in association with ischemic heart disease}

\section{Recommendations}

\section{A. Recommendations for hypertensive patients with CAD}

1. An ACE inhibitor or ARB is recommended for most patients with hypertension and CAD (Grade A).

2. For patients with stable angina, $\beta$-blockers are preferred as initial therapy (Grade B). CCBs may also be used (Grade B).
3. Short-acting nifedipine should not be used (Grade D).

4. For patients with CAD, but without coexisting systolic heart failure, the combination of an ACE inhibitor and $\mathrm{ARB}$ is not recommended (Grade $\mathrm{B}$ ).

5. In high-risk patients, when combination therapy is being used, choices should be individualized. The combination of an ACE inhibitor and a dihydropyridine CCB is preferable to an ACE inhibitor and a thiazide/thiazide-like diuretic in selected patients (Grade A).

6. When decreasing SBP to target levels in patients with established CAD (especially if isolated systolic hypertension is present), be cautious when the DBP is $\leq 60 \mathrm{~mm} \mathrm{Hg}$ because of concerns that myocardial ischemia might be exacerbated (Grade D) (new recommendation).

Background. Post hoc analyses of large clinical trials in patients with CAD suggest the existence of a possible J-curve, in which BP lowering to less than a specific nadir-which varies between studies - is associated with an increased risk of coronary events. ${ }^{49-51}$ This issue was discussed in detail in the 2013 CHEP recommendations. ${ }^{28}$ For 2014, after a rereview of the evidence, the RTF voted to add a new recommendation to advise caution if the DBP approaches $60 \mathrm{~mm} \mathrm{Hg}$ or less when striving to reach patient-specific SBP targets in patients with concomitant CAD. This situation arises most commonly when isolated systolic hypertension is present.

The recommendation to exercise caution with lowering $\mathrm{DBP}$ to $<60 \mathrm{~mm} \mathrm{Hg}$ is primarily derived from 3 studies; post hoc analyses of the Systolic Hypertension in Europe (Syst-Eur) trial, ${ }^{52}$ an observational coronary catheterization study, ${ }^{53}$ and a systematic review of the benefits of BP reduction in patients with CAD. ${ }^{54}$ In the Syst-Eur trial, ${ }^{52}$ cardiovascular event rates were increased when on-treatment DBP levels were $\leq 70 \mathrm{~mm} \mathrm{Hg}$ (independent of SBP levels) in older individuals (age $\geq 60$ years) with $\mathrm{CAD}$ receiving active antihypertensive treatment. This increase in cardiovascular events appeared to reach statistical significance at a DBP value of approximately $60 \mathrm{~mm} \mathrm{Hg}$. An observational coronary catheterization study ${ }^{3}$ demonstrated that when central DBP was $60 \mathrm{~mm} \mathrm{Hg}$ or less in hypertensive patients with CAD, the probability of reduced coronary blood flow distal to coronary stenosis was increased. Finally, a recent systematic review ${ }^{54}$ examining the beneficial and harmful effects of BP-lowering drugs in patients with CAD indicated that further reduction in cardiovascular disease event rates was small at SBP values less than $140 \mathrm{~mm} \mathrm{Hg}$ and should be weighed against the risk of hypotension.

Thus, there is Grade D evidence supporting the possibility of harm with excessive lowering of DBP in patients with established CAD. An alternative explanation might be that a lower DBP is a marker for frailty or medical illness and not causally related to increased events. ${ }^{55}$ Nevertheless, the RTF believed that the evidence was sufficiently robust to warrant bringing this issue to the attention of practitioners. The RTF wishes to emphasize that this suggests caution when lowering BP but does not preclude BP-lowering, especially in patients with moderate or severely increased SBP levels. A cautious approach might involve observing 
more carefully for signs and symptoms of reduced coronary blood flow while lowering SBP. This new recommendation does not apply to hypertensive patients without CAD. Finally, even in the context of CAD, other diagnoses such as diabetes or CKD might support further increases in antihypertensive therapy to lower SBP even when DBP values are $\leq 60 \mathrm{~mm} \mathrm{Hg}$.

B. Recommendations for patients with hypertension who have had a recent myocardial infarction

1. Initial therapy should include a $\beta$-blocker and an ACE inhibitor (Grade A).

2. An ARB can be used if the patient is intolerant of an ACE inhibitor (Grade A in patients with left ventricular systolic dysfunction).

3. CCBs may be used in patients after myocardial infarction when $\beta$-blockers are contraindicated or not effective. Nondihydropyridine CCBs should not be used when there is heart failure, evidenced by pulmonary congestion at time of examination or radiography (Grade D).

\section{Treatment of hypertension in association with heart failure}

\section{Recommendations}

1. In patients with systolic dysfunction (ejection fraction $<$ 40\%), ACE inhibitors (Grade A) and $\beta$-blockers (Grade A) are recommended for initial therapy. Aldosterone antagonists (mineralocorticoid receptor antagonists) might be added for patients with a recent cardiovascular hospitalization, acute myocardial infarction, elevated B-type natriuretic peptide or $\mathrm{N}$-terminal pro-B-type natriuretic peptide level, or New York Heart Association class II-IV symptoms (Grade A). Careful monitoring for hyperkalemia is recommended when adding an aldosterone antagonist to an ACE inhibitor or ARB. Other diuretics are recommended as additional therapy if needed (Grade B for thiazide/ thiazide-like diuretics for BP control, Grade D for loop diuretics for volume control). Beyond considerations of BP control, doses of ACE inhibitors or ARBs should be titrated to those found to be effective in trials unless adverse effects become manifest (Grade B).

2. An ARB is recommended if ACE inhibitors are not tolerated (Grade A).

3. A combination of hydralazine and isosorbide dinitrate is recommended if $\mathrm{ACE}$ inhibitors and $\mathrm{ARBs}$ are contraindicated or not tolerated (Grade B).

4. For hypertensive patients whose BP is not controlled, an ARB may be added to an ACE inhibitor and other antihypertensive drug treatment (Grade A). Careful monitoring should be used if combining an ACE inhibitor and an ARB because of potential adverse effects such as hypotension, hyperkalemia, and worsening renal function (Grade C). Additional therapies might also include dihydropyridine CCBs (Grade C).

Background. There are no changes to these recommendations for 2014.

\section{Treatment of hypertension in association with stroke}

\section{Recommendations}

A. BP management in acute stroke (onset to 72 hours)

1. For patients with ischemic stroke not eligible for thrombolytic therapy, treatment of hypertension in the setting of acute ischemic stroke or transient ischemic attack should not be routinely undertaken (Grade D). Extreme BP increases (eg, SBP > $220 \mathrm{~mm} \mathrm{Hg}$ or DBP $>120 \mathrm{~mm} \mathrm{Hg}$ ) may be treated to reduce the BP by approximately $15 \%$ (Grade D), and not more than $25 \%$, over the first 24 hours with gradual reduction thereafter (Grade D). Avoid excessive lowering of BP because this might exacerbate existing ischemia or might induce ischemia, particularly in the setting of intracranial arterial occlusion or extracranial carotid or vertebral artery occlusion (Grade D). Pharmacological agents and routes of administration should be chosen to avoid precipitous decreases in BP (Grade D).

2. For patients with ischemic stroke eligible for thrombolytic therapy, very high BP ( $>185 / 110 \mathrm{~mm} \mathrm{Hg}$ ) should be treated concurrently in patients receiving thrombolytic therapy for acute ischemic stroke to reduce the risk of secondary intracranial hemorrhage (Grade B).

\section{B. BP management after acute stroke}

1. Strong consideration should be given to the initiation of antihypertensive therapy after the acute phase of a stroke or transient ischemic attack (Grade A).

2. After the acute phase of a stroke, BP-lowering treatment is recommended to a target of consistently $<140 / 90$ mm Hg (Grade C).

3. Treatment with an ACE inhibitor and thiazide/thiazidelike diuretic combination is preferred (Grade $\mathrm{B}$ ).

4. For patients with stroke, the combination of an ACE inhibitor and ARB is not recommended (Grade B).

Background. There are no changes to these recommendations for 2014. However, 3 recent trials that examined SBP targets in stroke were discussed, ${ }^{56-58}$ and are briefly reviewed herein. Two examined BP-lowering after spontaneous intracerebral hemorrhage $(\mathrm{ICH}),{ }^{56,57}$ and 1 addressed BP-lowering 2 or more weeks after a symptomatic lacunar infarction. ${ }^{58}$ The results of these trials did not conclusively indicate benefit for greater BP reduction and no alterations were made to the recommendations at the present time.

The Intensive Blood Pressure Reduction in Acute Cerebral Hemorrhage Trial-2 (INTERACT-2) trial $^{56}$ enrolled 2839 individuals within 6 hours of spontaneous ICH. Investigators examined a strategy of lowering SBP within 1 hour of presentation to $<140 \mathrm{~mm} \mathrm{Hg}$ compared with $<180 \mathrm{~mm} \mathrm{Hg}$; these targets were to be maintained for at least 7 days. The primary outcome was a composite of death and disability defined by a score of 3-6 on the modified Rankin scale 90 days after the event. The outcome rate was greater than expected in both trial arms and the between-group differences were less than expected. There was a suggestion of a $13 \%$ relative reduction $(0.87 ; 95 \% \mathrm{CI}, 0.75-1.01)$ in the primary outcome favouring the lower SBP target group but as 
demonstrated by the $95 \% \mathrm{CI}$, this finding was not conclusive. Therefore, the RTF was of the view that the strength of evidence did not warrant a change in recommendations.

Intracerebral Hemorrhage Acutely Decreasing Arterial Pressure Trial (ICH ADAPT) ${ }^{57}$ enrolled patients within 24 hours of a spontaneous ICH if their SBP was $\geq 150 \mathrm{~mm} \mathrm{Hg}$. The SBP targets were $<150 \mathrm{~mm} \mathrm{Hg}$ vs $<180 \mathrm{~mm} \mathrm{Hg}$. The primary outcome was radiographically-determined perihematoma relative cerebral blood flow $(\mathrm{rCBF})$ and the main objective was to examine whether SBP-lowering had a detrimental effect on rCBF. Seventy-five participants were enrolled. No conclusive differences in perihematoma $\mathrm{rCBF}$ were demonstrated (perihematoma rCBF difference, 0.03; $95 \% \mathrm{CI},-0.018$ to 0.078$)$. The ipsilateral hemispheric $\mathrm{rCBF}$ was slightly less in the lower BP target group (0.04 difference), suggesting lower perfusion with a lower BP target, although the magnitude of the difference was small. The investigators interpreted their findings as suggesting no detrimental effect on perihematoma $\mathrm{rCBF}$ with BP reduction after $\mathrm{ICH}$.

The Secondary Prevention of Small Subcortical Strokes (SPS3) trial $^{58}$ enrolled 3020 patients with magnetic resonance imaging-defined symptomatic lacunar infarctions (ie, small subcortical strokes) and without surgically amenable ipsilateral carotid artery stenosis or high-risk cardioembolic sources. Participants were enrolled 2 weeks after stroke and were randomized to $<130 \mathrm{~mm} \mathrm{Hg}$ vs $130-149 \mathrm{~mm} \mathrm{Hg} \mathrm{SBP}$ targets. After 3.7 years, there was no conclusive difference in either the incidence of recurrent stroke (HR, 0.81; 95\% CI, 0.64-1.03) or the occurrence of adverse events (orthostatic syncope HR, 2.19; 95\% CI, 0.76-6.27; all adverse events HR, 1.53; 95\% CI, 0.80-2.93); the RTF noted, however, that the point estimates suggested lower recurrent stroke rates but higher adverse event rates in the $<130 \mathrm{~mm} \mathrm{Hg} \mathrm{SBP}$ target group.

\section{Treatment of hypertension in association with left ventricular hypertrophy}

\section{Recommendations}

1. Hypertensive patients with left ventricular hypertrophy should be treated with antihypertensive therapy to lower the rate of subsequent cardiovascular events (Grade C).

2. The choice of initial therapy can be influenced by the presence of left ventricular hypertrophy (Grade D). Initial therapy can be drug treatment using ACE inhibitors, ARBs, long-acting CCBs, or thiazide/thiazide-like diuretics. Direct arterial vasodilators such as hydralazine or minoxidil should not be used.

Background. There are no changes to these recommendations for 2014.

\section{$X$. Treatment of hypertension in association with nondiabetic CKD}

\section{$\underline{\text { Recommendations }}$}

1. For patients with nondiabetic CKD, target $\mathrm{BP}$ is $<140 / 90$ $\mathrm{mm} \mathrm{Hg}$ (Grade B).

2. For patients with hypertension and proteinuric $\mathrm{CKD}$ (urinary protein $>500 \mathrm{mg}$ per 24 hours or albumin to creatinine ratio $>30 \mathrm{mg} / \mathrm{mmol}$ ), initial therapy should be an ACE inhibitor (Grade A) or an ARB if there is intolerance to ACE inhibitors (Grade B).

3. Thiazide/thiazide-like diuretics are recommended as additive antihypertensive therapy (Grade D). For patients with $\mathrm{CKD}$ and volume overload, loop diuretics are an alternative (Grade D).

4. In most cases, combination therapy with other antihypertensive agents might be needed to reach target BP levels (Grade D).

5. The combination of an ACE inhibitor and ARB is not recommended for patients with nonproteinuric CKD (Grade B).

Background. There are no changes to these recommendations for 2014 .

\section{Treatment of hypertension in association with renovascular disease}

\section{Recommendations}

1. Renovascular hypertension should be treated in the same manner as hypertension without compelling indications, except for caution in the use of ACE inhibitors or ARBs because of the risk of acute renal failure in bilateral disease or unilateral disease with a solitary kidney (Grade D).

2. Close follow-up and early intervention (angioplasty and stenting or surgery) should be considered for patients with uncontrolled hypertension despite therapy with $\geq 3$ drugs, deteriorating kidney function, bilateral atherosclerotic renal artery lesions (or tight atherosclerotic stenosis in a single kidney), or recurrent episodes of flash pulmonary edema (Grade D).

Background. There are no changes to these recommendations for 2014.

\section{Treatment of hypertension in association with diabetes mellitus}

\section{Recommendations}

1. Persons with diabetes mellitus should be treated to attain SBP of $<130 \mathrm{~mm} \mathrm{Hg}$ (Grade C) and DBP of $<80 \mathrm{~mm}$ $\mathrm{Hg}$ (Grade A) (these target BP levels are the same as the BP treatment thresholds). Combination therapy using 2 firstline agents might also be considered as initial treatment of hypertension (Grade B) if SBP is $20 \mathrm{~mm} \mathrm{Hg}$ greater than target or if DBP is $10 \mathrm{~mm} \mathrm{Hg}$ greater than target. However, caution should be exercised in patients in whom a substantial decrease in BP is more likely or poorly tolerated (eg, elderly patients and patients with autonomic neuropathy).

2. For persons with cardiovascular or kidney disease, including microalbuminuria, or with cardiovascular risk factors in addition to diabetes and hypertension, an ACE inhibitor or an ARB is recommended as initial therapy (Grade A).

3. For persons with diabetes and hypertension not included in other recommendations in this section, appropriate choices 
Table 1. Considerations in the individualization of pharmacological therapy

\begin{tabular}{|c|c|c|}
\hline & Initial therapy & Second-line therapy \\
\hline \multicolumn{3}{|c|}{ Hypertension without other compelling indications } \\
\hline $\begin{array}{l}\text { Diastolic hypertension with or } \\
\text { without systolic hypertension } \\
\text { (target BP }<140 / 90 \mathrm{~mm} \mathrm{Hg} \text { ) }\end{array}$ & $\begin{array}{l}\text { Thiazide/thiazide-like diuretics, } \beta \text { - } \\
\text { blockers, ACE inhibitors, ARBs, or } \\
\text { long-acting CCBs (consider ASA } \\
\text { and statins in selected patients). } \\
\text { Consider initiating therapy with a } \\
\text { combination of first-line drugs if the } \\
\text { BP is } \geq 20 \mathrm{~mm} \mathrm{Hg} \text { systolic or } \geq 10 \\
\mathrm{~mm} \mathrm{Hg} \text { diastolic greater than target }\end{array}$ & Combinations of first-line drugs \\
\hline
\end{tabular}

\section{Isolated systolic hypertension} without other compelling indications (target $\mathrm{BP}$ for age $<80$ is $<140 / 90 \mathrm{~mm} \mathrm{Hg}$; for age $\geq 80$ : target $\mathrm{SBP}$ is $<150$ $\mathrm{mm} \mathrm{Hg}$

Diabetes mellitus (target $\mathrm{BP}<130 / 80 \mathrm{~mm} \mathrm{Hg}$ )

Diabetes mellitus with ACE inhibitors or ARBs

microalbuminuria, ${ }^{*}$ renal disease,

cardiovascular disease, or

additional cardiovascular risk

factors

Diabetes mellitus not included in the above category

ACE inhibitors, ARBs, dihydropyridine CCBs, or thiazide/ thiazide-like diuretics

\section{Cardiovascular disease (target BP $<140 / 90 \mathrm{~mm} \mathrm{Hg}$ ) \\ Coronary artery disease \\ ACE inhibitors or ARBs; $\beta$-blockers \\ for patients with stable angina} inhibitor-intolerant) and $\beta$-blockers. (mineralocorticoid receptor
Addition of a dihydropyridine CCB is preferred over a thiazide/thiazidelike diuretic

Combination of first-line drugs. If combination with ACE inhibitor is being considered, a dihydropyridine $\mathrm{CCB}$ is preferable to a thiazide/ thiazide-like diuretic

Long-acting CCBs. When for high-risk patients, an ACE inhibitor/dihydropyridine CCB is preferred

Long-acting CCBs if $\beta$-blocker contraindicated or not effective

ACE inhibitor and ARB combined. Hydralazine/isosorbide dinitrate combination if ACE inhibitor and $\mathrm{ARB}$ contraindicated or not tolerated.

Thiazide/thiazide-like or loop diuretics are recommended as additive therapy. Dihydropyridine CCBs can also be used
Not recommended for monotherapy: $\alpha$-blockers, $\beta$-blockers in those $\geq 60$ years of age, and ACE inhibitors in black people. Hypokalemia should be avoided in those prescribed diuretics. ACE inhibitors, ARBs, and direct renin inhibitors are potential teratogens, and caution is required if prescribing to women with child-bearing potential. Combination of an ACE-inhibitor with an ARB is not recommended Same as diastolic hypertension with or without systolic hypertension
Recent myocardial infarction

$\beta$-Blockers and ACE inhibitors (ARBs if ACE inhibitor-intolerant)

Heart failure

Left ventricular hypertrophy

Past stroke or TIA

ACE inhibitors (ARBs if ACE Aldosterone antagonists antagonists) may be added for patients with a recent cardiovascular hospitalization, acute myocardial infarction, elevated BNP or NTproBNP level, or NYHA class II-IV symptoms

ACE inhibitor, ARB, long-acting CCB Combination of additional agents or thiazide/thiazide-like diuretics.

ACE inhibitor and a thiazide/thiazide- Combination of additional agents like diuretic combination combination therapy is being used

Avoid short-acting nifedipine. Combination of an ACE inhibitor with an ARB is specifically not recommended. Exercise caution when decreasing SBP to target if DBP is $\leq 60 \mathrm{~mm} \mathrm{Hg}$

Nondihydropyridine CCBs should not be used with concomitant heart failure

Titrate doses of ACE inhibitors and ARBs to those used in clinical trials. Carefully monitor potassium and renal function if combining any of ACE inhibitor, ARB, and/or aldosterone antagonist

Hydralazine and minoxidil should not be used

Treatment of hypertension should not be routinely undertaken in acute stroke unless extreme BP increase. Combination of an ACE inhibitor with an ARB is not recommended

\section{Nondiabetic CKD (target BP $<140 / 90$ mm Hg)}

Nondiabetic CKD with proteinuria ${ }^{\dagger}$ ACE inhibitors (ARBs if ACE inhibitor-intolerant) if there is proteinuria; diuretics as additive therapy

Renovascular disease

Does not affect initial treatment recommendations
Combinations of additional agents

Combinations of additional agents
Carefully monitor renal function and potassium for those taking an ACE an ACE inhibitor and ARB are not recommended in patients without proteinuria

Avoid ACE inhibitors or ARBs if bilateral renal artery stenosis or unilateral disease with solitary kidney inhibitor or ARB. Combinations of 
Table 1. Continued.

\begin{tabular}{|c|c|c|c|}
\hline & Initial therapy & Second-line therapy & Notes and/or cautions \\
\hline \multicolumn{4}{|c|}{ Other conditions (target $\mathrm{BP}<140 / 90 \mathrm{~mm} \mathrm{Hg}$ ) } \\
\hline Peripheral arterial disease & $\begin{array}{l}\text { Does not affect initial treatment } \\
\text { recommendations }\end{array}$ & Combinations of additional agents & Avoid $\beta$-blockers with severe disease \\
\hline Dyslipidemia & $\begin{array}{l}\text { Does not affect initial treatment } \\
\text { recommendations }\end{array}$ & Combinations of additional agents & - \\
\hline Overall vascular protection & $\begin{array}{l}\text { Statin therapy for patients } \geq 3 \\
\text { cardiovascular risk factors or } \\
\text { atherosclerotic disease; low-dose } \\
\text { ASA in patients } \geq 50 \text { years }\end{array}$ & - & $\begin{array}{l}\text { Caution should be exercised with the } \\
\text { ASA recommendation if BP is not } \\
\text { controlled }\end{array}$ \\
\hline
\end{tabular}

ACE, angiotensin-converting enzyme; ACR, albumin to creatinine ratio; ARB, angiotensin receptor blocker; ASA, acetylsalicylic acid; BNP, B-type natriuretic peptide; BP, blood pressure; CCB, calcium channel blocker; CKD, chronic kidney disease; DBP, diastolic blood pressure; NT, N-terminal; NYHA, New York Heart Association; SBP, systolic blood pressure; TIA, transient ischemic attack.

${ }^{*}$ Microalbuminuria is defined as persistent ACR $>2.0 \mathrm{mg} / \mathrm{mmol}$.

${ }^{\dagger}$ Proteinuria is defined as urinary protein $>500 \mathrm{mg}$ per 24 hours or ACR $>30 \mathrm{mg} / \mathrm{mmol}$ in 2 of 3 specimens.

Reproduced with permission of the Canadian Hypertension Education Program.

include (in alphabetical order): ACE inhibitors (Grade A), ARBs (Grade B), dihydropyridine CCBs (Grade A), and thiazide/thiazide-like diuretics (Grade A).

4. If target BP levels are not achieved with standard-dose monotherapy, additional antihypertensive therapy should be used. For persons in whom combination therapy with an ACE inhibitor is being considered, a dihydropyridine $\mathrm{CCB}$ is preferable to a thiazide/thiazide-like diuretic (Grade A).

Background. There are no changes to these recommendations for 2014.

\section{Adherence strategies for patients}

\section{Recommendations}

1. Adherence to an antihypertensive prescription can be improved by a multipronged approach (Supplemental Table S12).

Background. There are no changes to these recommendations for 2014.

\section{Treatment of secondary hypertension because of endocrine causes}

\section{$\underline{\text { Recommendations }}$}

1. Treatment of hyperaldosteronism and pheochromocytoma are outlined in Supplemental Tables S7 and S8, respectively.

Background. There are no changes to these recommendations for 2014.

\section{Implementation}

The implementation task force conducts an extensive knowledge translation effort to enhance uptake and applicability of these recommendations. These efforts include knowledge exchange forums, targeted educational materials for primary care providers and patients, and freely available slide kits and summary documents of all recommendations on the Canadian Hypertension Society Web site, Hypertension Canada (www.hypertension.ca). Documents are available in French and English, and some documents are translated into other languages. The implementation task force also regularly receives feedback from end users to improve guideline processes and content. Although the number of primary care providers who directly receive CHEP materials on a regular basis has dramatically increased, CHEP is continuing to address the challenge of identifying and reaching all active primary care providers across Canada, through use of the Hypertension Canada Web site, "Train the Trainer" teaching sessions, and wide dissemination of educational materials.

The CHEP outcomes task force conducts hypertension surveillance studies and reviews existing Canadian health surveys to identify gaps between current and best practices.

\section{Future Directions}

Table 1 contains a summary of pharmacological management recommendations for hypertension. The present article represents the 14th iteration of the annually updated CHEP recommendations for the management of hypertension. The RTF will continue to conduct systematic reviews of the clinical trial evidence and update these recommendations annually.

\section{Acknowledgements}

The authors thank Ms Susan Carter for expert technical assistance with the manuscript.

\section{Funding Sources}

The CHEP is operated and funded by Hypertension Canada. The members of the CHEP Committee are unpaid volunteers who contribute their time and expertise to the annual development and dissemination of the CHEP recommendations. To maintain professional credibility of the content, the process for the development of the recommendations is fully independent and free from external influence. External partners assist with the dissemination of the approved recommendations. 


\section{Disclosures}

Please see Supplemental Appendix S2 for a complete list of author disclosures.

\section{References}

1. McAlister FA, Wilkins K, Joffres M, et al. Changes in the rates of awareness, treatment and control of hypertension in Canada over the past two decades. CMAJ 2011;183:1007-13.

2. Robitaille C, Dai S, Waters C, et al. Diagnosed hypertension in Canada: incidence, prevalence and associated mortality. CMAJ 2012;184:E49-56.

3. Kannel WB. Blood pressure as a cardiovascular risk factor: prevention and treatment. JAMA 1996;275:1571-6.

4. Yusuf S, Hawkins S, Ounpuu S, et al. Effect of potentially modifiable risk factors associated with myocardial infarction in 52 countries (the INTERHEART study): case-control study. Lancet 2004;364:937-52.

5. Chow CK, Teo KK, Rangarajan S, et al. Prevalence, awareness, treatment, and control of hypertension in rural and urban communities in high-, middle-, and low-income countries. JAMA 2013;310:959-68.

6. Lim SS, Vos T, Flaxman AD, et al. A comparative risk assessment of burden of disease and injury attributable to 67 risk factors and risk factor clusters in 21 regions, 1990-2010: a systematic analysis for the Global Burden of Disease Study 2010. Lancet 2012;380:2224-60.

7. Feldman RD, Campbell N, Larochelle P, et al. 1999 Canadian recommendations for the management of hypertension. Task Force for the Development of the 1999 Canadian Recommendations for the Management of Hypertension. CMAJ 1999;161(Suppl 12):S1-17.

8. Zarnke KB, Levine M, McAlister FA, et al. The 2000 Canadian recommendations for the management of hypertension: part two-diagnosis and assessment of people with high blood pressure. Can J Cardiol 2001;17:1249-63.

9. Zarnke KB, McAlister FA, Campbell NR, et al. The 2001 Canadian recommendations for the management of hypertension: Part oneassessment for diagnosis, cardiovascular risk, causes and lifestyle modification. Can J Cardiol 2002;18:604-24.

10. McAlister FA, Zarnke KB, Campbell NR, et al. The 2001 Canadian recommendations for the management of hypertension: part twotherapy. Can J Cardiol 2002;18:625-41.

11. Hemmelgarn BR, Zarnke KB, Campbell NR, et al. The 2004 Canadian Hypertension Education Program recommendations for the management of hypertension: part I-blood pressure measurement, diagnosis and assessment of risk. Can J Cardiol 2004;20:31-40.

12. Khan NA, McAlister FA, Campbell NR, et al. The 2004 Canadian recommendations for the management of hypertension: part II-therapy. Can J Cardiol 2004;20:41-54.

13. Touyz RM, Campbell N, Logan A, et al. The 2004 Canadian recommendations for the management of hypertension: part III-lifestyle modifications to prevent and control hypertension. Can J Cardiol 2004;20:55-9.

14. Hemmelgarn BR, McAllister FA, Myers MG, et al. The 2005 Canadian Hypertension Education Program recommendations for the management of hypertension: part 1- blood pressure measurement, diagnosis and assessment of risk. Can J Cardiol 2005;21:645-56.

15. Khan NA, McAlister FA, Lewanczuk RZ, et al. The 2005 Canadian Hypertension Education Program recommendations for the management of hypertension: part II - therapy. Can J Cardiol 2005;21:657-72.
16. Hemmelgarn BR, McAlister FA, Grover S, et al. The 2006 Canadian Hypertension Education Program recommendations for the management of hypertension: part I-blood pressure measurement, diagnosis and assessment of risk. Can J Cardiol 2006;22:573-81.

17. Khan NA, McAlister FA, Rabkin SW, et al. The 2006 Canadian Hypertension Education Program recommendations for the management of hypertension: part II - therapy. Can J Cardiol 2006;22:583-93.

18. Padwal RS, Hemmelgarn BR, McAlister FA, et al. The 2007 Canadian Hypertension Education Program recommendations for the management of hypertension: part 1- blood pressure measurement, diagnosis and assessment of risk. Can J Cardiol 2007;23:529-38.

19. Khan NA, Hemmelgarn B, Padwal R, et al. The 2007 Canadian Hypertension Education Program recommendations for the management of hypertension: part 2-therapy. Can J Cardiol 2007;23:539-50.

20. Padwal RS, Hemmelgarn BR, Khan NA, et al. The 2008 Canadian Hypertension Education Program recommendations for the management of hypertension: part 1-blood pressure measurement, diagnosis and assessment of risk. Can J Cardiol 2008;24:455-63.

21. Khan NA, Hemmelgarn B, Herman RJ, et al. The 2008 Canadian Hypertension Education Program recommendations for the management of hypertension: part 2-therapy. Can J Cardiol 2008;24:465-75.

22. Padwal RS, Hemmelgarn BR, Khan NA, et al. The 2009 Canadian Hypertension Education Program recommendations for the management of hypertension: part 1-blood pressure measurement, diagnosis and assessment of risk. Can J Cardiol 2009;25:279-86.

23. Khan NA, Hemmelgarn B, Herman RJ, et al. The 2009 Canadian Hypertension Education Program recommendations for the management of hypertension: part 2-therapy. Can J Cardiol 2009;25:287-98.

24. Quinn RR, Hemmelgarn BR, Padwal RS, et al. The 2010 Canadian Hypertension Education Program recommendations for the management of hypertension: part I-blood pressure measurement, diagnosis and assessment of risk. Can J Cardiol 2010;26:241-8.

25. Hackam DG, Khan NA, Hemmelgarn BR, et al. The 2010 Canadian Hypertension Education Program recommendations for the management of hypertension: part 2-therapy. Can J Cardiol 2010;26:249-58.

26. Rabi DM, Daskalopoulou SS, Padwal RS, et al. The 2011 Canadian Hypertension Education Program recommendations for the management of hypertension: blood pressure measurement, diagnosis, assessment of risk, and therapy. Can J Cardiol 2011;27:415-33.

27. Daskalopoulou SS, Khan NA, Quinn RR, et al. The 2012 Canadian Hypertension Education Program recommendations for the management of hypertension: blood pressure measurement, diagnosis, assessment of risk, and therapy. Can J Cardiol 2012;28:270-87.

28. Hackam DG, Quinn RR, Ravani P, et al. The 2013 Canadian Hypertension Education Program recommendations for blood pressure measurement, diagnosis, assessment of risk, prevention, and treatment of hypertension. Can J Cardiol 2013;29:528-42.

29. McAlister FA. The Canadian Hypertension Education Program-a unique Canadian initiative. Can J Cardiol 2006;22:559-64.

30. Brouwers MC, Kho ME, Browman GP, et al. AGREE II: advancing guideline development, reporting and evaluation in health care. CMAJ 2010;182:E839-42.

31. Bennett CM, Guo M, Dharmage SC. HbA(1c) as a screening tool for detection of Type 2 diabetes: a systematic review. Diabet Med 2007;24: $333-43$. 
32. Hu Y, Liu W, Chen Y, et al. Combined use of fasting plasma glucose and glycated hemoglobin $\mathrm{Alc}$ in the screening of diabetes and impaired glucose tolerance. Acta Diabetol 2010;47:231-6.

33. Canadian Diabetes Association Clinical Practice Guidelines Expert Committee. Canadian Diabetes Association 2013 clinical practice guidelines for the prevention and management of diabetes in Canada. Can J Diabetes 2013;37(suppl 1):S1-212.

34. Sacks F, Svetkey L, Vollmer W, et al. Effects on blood pressure of reduced dietary sodium and the dietary approaches to stop hypertension (DASH) diet. N Engl J Med 2001;344:3-10.

35. Moore TJ, Vollmer WM, Appel LJ, et al. Effect of dietary patterns on ambulatory blood pressure: results from the Dietary Approaches to Stop Hypertension (DASH) Trial. DASH Collaborative Research Group. Hypertension 1999;34:472-7.

36. Karanja NM, Obarzanek E, Lin PH, et al. Descriptive characteristics of the dietary patterns used in the Dietary Approaches to Stop Hypertension Trial. DASH Collaborative Research Group. J Am Diet Assoc 1999;99(suppl 8):S19-27.

37. Appel L, Moore T, Obarzanek E, et al. A clinical trial of the effects of dietary patterns on blood pressure. N Engl J Med 1997;336:1117-24.

38. He FJ, Li J, Macgregor GA. Effect of longer term modest salt reduction on blood pressure: Cochrane systematic review and meta-analysis of randomised trials. BMJ 2013;346:f1325.

39. Aburto NJ, Ziolkovska A, Hooper L, et al. Effect of lower sodium intake on health: systematic review and meta-analyses. BMJ 2013;346:f1326.

40. Institute of Medicine of the National Academies. Sodium intake in populations: assessment of evidence. Available at: www.iom.edu/ sodiumconsequences. Accessed March 19, 2014.

41. Beckett NS, Peters R, Fletcher AE, et al. Treatment of hypertension in patients 80 years of age or older. N Engl J Med 2008;358:1887-98.

42. Beckett N, Peters R, Tuomilehto J, et al. Immediate and late benefits of treating very elderly people with hypertension: results from active treatment extension to Hypertension in the Very Elderly randomised controlled trial. BMJ 2012;344:d7541.

43. Gueyffier F, Bulpitt C, Boissel JP, et al. Antihypertensive drugs in very old people: a subgroup meta-analysis of randomised controlled trials. INDANA Group. Lancet 1999;353:793-6.

44. Hansson L, Zanchetti A, Carruthers SG, et al. Effects of intensive bloodpressure lowering and low-dose aspirin in patients with hypertension: principal results of the Hypertension Optimal Treatment (HOT) randomised trial. HOT Study Group. Lancet 1998;351:1755-62.

45. Hansson L, Zanchetti A; for the HOT Study Group. The hypertension optimal treatment study (the HOT study). Blood Press 1993;2:62-8.

46. Calonge N, Petitti DB, DeWitt TG, Gordis L. Aspirin for the prevention of cardiovascular disease: U.S. Preventive Services Task Force recommendation statement. Ann Intern Med 2009;150:396-404.
47. Rothwell PM, Fowkes FG, Belch JF, et al. Effect of daily aspirin on longterm risk of death due to cancer: analysis of individual patient data from randomised trials. Lancet 2011;377:31-41.

48. Vandvik PO, Lincoff AM, Gore JM, et al. Primary and secondary prevention of cardiovascular disease: Antithrombotic Therapy and Prevention of Thrombosis, 9th ed: American College of Chest Physicians Evidence-Based Clinical Practice Guidelines [erratum in 2012;141: 1129]. Chest 2012;141(suppl 2):e637S-68S.

49. Messerli FH, Mancia G, Conti CR, et al. Dogma disputed: can aggressively lowering blood pressure in hypertensive patients with coronary artery disease be dangerous? Ann Intern Med 2006;144:884-93.

50. Bangalore S, Messerli FH, Wun CC, et al. J-curve revisited: an analysis of blood pressure and cardiovascular events in the Treating to New Targets (TNT) Trial. Eur Heart J 2010;31:2897-908.

51. Bangalore S, Qin J, Sloan S, Murphy SA, Cannon CP. What is the optimal blood pressure in patients after acute coronary syndromes?: Relationship of blood pressure and cardiovascular events in the PRavastatin OR atorVastatin Evaluation and Infection Therapy-Thrombolysis In Myocardial Infarction (PROVE IT-TIMI) 22 trial. Circulation 2010;122:2142-51.

52. Fagard RH, Staessen JA, Thijs L, et al. On-treatment diastolic blood pressure and prognosis in systolic hypertension. Arch Intern Med 2007;167:1884-91.

53. Rabkin SW, Waheed A, Poulter RS, Wood D. Myocardial perfusion pressure in patients with hypertension and coronary artery disease: implications for DBP targets in hypertension management. J Hypertens 2013;31:975-82.

54. Bangalore S, Kumar S, Volodarskiy A, Messerli FH. Blood pressure targets in patients with coronary artery disease: observations from traditional and Bayesian random effects meta-analysis of randomised trials. Heart 2013;99:601-13.

55. Verdecchia P, Angeli F, Mazzotta G, Garofoli M, Reboldi G. Aggressive blood pressure lowering is dangerous: the J-curve: con side of the argument. Hypertension 2013. [Epub ahead of print].

56. Anderson CS, Heeley E, Huang Y, et al. Rapid blood-pressure lowering in patients with acute intracerebral hemorrhage. $N$ Engl J Med 2013;368:2355-65.

57. Butcher KS, Jeerakathil T, Hill M, et al. The Intracerebral Hemorrhage Acutely Decreasing Arterial Pressure Trial. Stroke 2013;44:620-6.

58. Benavente OR, Coffey CS, Conwit R, et al. Blood pressure targets in patients with recent lacunar stroke: the SPS3 randomised trial. Lancet 2013;382:507-15.

\section{Supplementary Material}

To access the supplementary material accompanying this article, visit the online version of the Canadian Journal of Cardiology at www.onlinecjc.ca and at http://dx.doi.org/10. 1016/j.cjca.2014.02.002. 